\title{
Sensitivity of the simulated precipitation to changes in convective relaxation time scale
}

\author{
S. K. Mishra ${ }^{1,2}$ and J. Srinivasan ${ }^{3,4}$ \\ ${ }^{1}$ National Center for Atmospheric Research, Boulder, CO, USA \\ ${ }^{2}$ Department of Computer Science, University of Colorado, Boulder, CO, USA \\ ${ }^{3}$ Divecha Centre for Climate Change, Bangalore, India \\ ${ }^{4}$ Centre for Atmospheric and Oceanic Sciences, Indian Institute of Science, Bangalore, India
}

Received: 4 March 2010 - Revised: 11 August 2010 - Accepted: 26 August 2010 - Published: 6 October 2010

\begin{abstract}
The paper describes the sensitivity of the simulated precipitation to changes in convective relaxation time scale (TAU) of Zhang and McFarlane (ZM) cumulus parameterization, in NCAR-Community Atmosphere Model version 3 (CAM3). In the default configuration of the model, the prescribed value of TAU, a characteristic time scale with which convective available potential energy (CAPE) is removed at an exponential rate by convection, is assumed to be $1 \mathrm{~h}$. However, some recent observational findings suggest that, it is larger by around one order of magnitude. In order to explore the sensitivity of the model simulation to TAU, two model frameworks have been used, namely, aquaplanet and actual-planet configurations. Numerical integrations have been carried out by using different values of TAU, and its effect on simulated precipitation has been analyzed.

The aqua-planet simulations reveal that when TAU increases, rate of deep convective precipitation (DCP) decreases and this leads to an accumulation of convective instability in the atmosphere. Consequently, the moisture content in the lower- and mid- troposphere increases. On the other hand, the shallow convective precipitation (SCP) and large-scale precipitation (LSP) intensify, predominantly the SCP, and thus capping the accumulation of convective instability in the atmosphere. The total precipitation (TP) remains approximately constant, but the proportion of the three components changes significantly, which in turn alters the vertical distribution of total precipitation production. The vertical structure of moist heating changes from a vertically extended profile to a bottom heavy profile, with the increase of TAU. Altitude of the maximum vertical velocity shifts from upper troposphere to lower troposphere. Similar response was seen
\end{abstract}

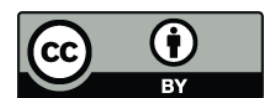

Correspondence to: S. K. Mishra (saroj@ucar.edu) in the actual-planet simulations. With an increase in TAU from $1 \mathrm{~h}$ to $8 \mathrm{~h}$, there was a significant improvement in the simulation of the seasonal mean precipitation. The fraction of deep convective precipitation was in much better agreement with satellite observations.

Keywords. Meteorology and atmospheric dynamics (Precipitation)

\section{Introduction}

The precipitation in many general circulation models (GCMs) has three components, namely, deep convective, shallow convective and large-scale precipitation. In the convective parameterization schemes used in GCMs there are many tunable parameters. Some of the parameters are observable (e.g., particle size distribution), while many others are not (e.g., convective relaxation time scale). The selection of suitable values for these unobservable parameters is one of the most challenging tasks. Since, these parameters are free and disposable, their values are deduced by an indirect method. The usual method followed, is to find the effect of a parameter on the model simulation, and then choose a value, which maximizes agreement with observations (Mapes, 2001). These parameters are considered to be the weakest link in the chain of the parameterization (Mapes, 2001).

The convective relaxation time scale (TAU, also known as convective adjustment time scale) is one of the parameters, which influences the model simulation significantly (Mishra, 2007; Lee et at., 2009). The definition and function of TAU is described in Sect. 4.2.

It was a long-standing belief that the TAU is on the order of $1 \mathrm{~h}$ to $2 \mathrm{~h}$. Betts (1986) used a single column model and

Published by Copernicus Publications on behalf of the European Geosciences Union. 
showed that, when the value of TAU was set to approximately $2 \mathrm{~h}$, the observed features (e.g., wave structure and amplitude observed during the GATE experiment) were accurately reproduced. Following Betts (1986), the value of TAU has been used as approximately $1-2 \mathrm{~h}$ in most of the present day GCMs. The standard value of TAU in NCAR-CAM3 is $1 \mathrm{~h}$, which uses the Zhang-McFarlane (ZM) convection scheme (Collins et al., 2004). In Canadian Center for Climate Modeling and Analysis (CCCma) AGCM3, TAU is set to $40 \mathrm{~min}$, which also uses the ZM scheme (Lorant et al., 2006). Ricciardulli and Garcia (2000) used TAU $=2 \mathrm{~h}$ in $\mathrm{CCM} 3$, which is an older version of CAM3. On the contrary recent studies suggested that, adjustment time scale is scale dependent and should be on the order of $12 \mathrm{~h}$ for $300 \mathrm{~km}$ horizontal resolution (Bretherton et al., 2004; Lee et al., 2009). Hence it is important to investigate the sensitivity of the model simulation to changes in TAU. Recently, Frierson (2007) used a range of values for TAU, starting from $1 \mathrm{~h}$ to $16 \mathrm{~h}$ in an idealized model with a simplified convection scheme (similar to Betts-Miller scheme) in a gray-radiation aqua-planet moist GCM. He showed that the model simulation is not sensitive to TAU. However, in his simplified model, there are no cloud and water vapor radiative feedbacks. So, it is necessary to investigate if the model simulation is sensitive to TAU in a full GCM with water vapor and radiative feedbacks, which is the focus of this study. Since precipitation is one of the most important components of the Earth's climate system, its simulation is examined in detail in this paper. We have carried out experiments with NCAR-CAM3 with different values of TAU. Most of the investigation has been carried out in an aqua-planet framework. We have also conducted simulations in the real-planet framework to verify that our inferences based on aqua-planet simulation are relevant to the actual planet.

The model components are briefly described in Sect. 2, and the experiments are described in Sect. 3. The results are discussed in Sect. 4 and conclusions are presented in Sect. 5.

\section{Description of the model}

The Community Atmosphere Model version 3 (CAM3) is a sixth generation atmospheric general circulation model (AGCM) developed by the atmospheric modeling community in collaboration with the National Center for Atmospheric Research (NCAR). The source code, documentation and input datasets for the model was obtained from the CAM website (http://www.ccsm.ucar.edu/models/atm-cam).

CAM3 is designed to produce simulations with reasonable accuracy for various dynamical cores and horizontal resolutions (Collins et al., 2006; Hack et al., 2006; Hurrel et al., 2006; Meehl et al., 2006; Rasch et al., 2006;). For this study semi-Lagrangian dynamical (SLD) core was used at $128 \times 64$ horizontal resolution with 26 vertical levels. The model uses the hybrid vertical coordinate, which is terrain following at earth's surface, but reduces to pressure coordinate at higher levels near the tropopause.

The moist precipitation process consists of deep convective, shallow convective and stratiform processes. The physical parameterization schemes include those for deep convective (Zhang and McFarlane, 1995), shallow convective (Hack, 1994) and stratiform processes (Rasch and Kristjansson, 1998; Zhang et al., 2003). The updraft ensembles in ZM are deep penetrative in nature, which rooted in the planetary boundary layer and penetrate into the upper troposphere until their neutral buoyancy levels. The top of the "shallowest" of the convective plumes is assumed to be no lower than the height of the minimum in saturated moist static energy (typically in the mid-troposphere). On the contrary, HK uses a simple cloud model based on triplets, in which convective instability is assessed for three adjacent layers in the vertical. If a parcel of air in the lower layer is more buoyant than one in the middle layer, adjustment occurs. So, unlike the deep penetrative plume of ZM scheme, HK can have both shallow and deep plumes, but no plume in HK is deeper than the thickness of 3-model layers. Secondly, in the tropical atmosphere the typical MSE has its minima in the mid-troposphere, so the triplet cloud model mainly works in the lower and middle troposphere. The above discussed designed principle of HK scheme is such, even when ZM scheme is inactive/absent, where only HK was operating, it could not produce plumes which are deeper than 3 model layers. So, it is more like a local scheme that primarily does shallow and mid-level convection.

Separate evolution equations have been included for the liquid and ice phase condensate. Condensed water detrained from shallow and frontal convection can either form precipitation or additional stratiform cloud water. Convective precipitation can evaporate into its environment at a rate determined from Sundqvist (1988).

Equations governing cloud condensate include advection and sedimentation of cloud droplets and ice particles. The settling velocities for liquid and ice-phase constituents are computed separately as functions of particle size characterized by the effective radius. Small ice particles are assumed to fall like spheres according to the Stokes equation. With the increase in size of the ice particles, there is a smooth transition to a different formulation for fall speeds following Locatelli and Hobbs (1974). In the case of liquid drops, fall velocities are calculated using Stokes equation for the entire range of sizes.

To insure conservation of energy (Boville and Bretherton, 2003), the calculation of thermodynamic tendencies was reformulated. The dry static energy is predicted by each physical parameterization and is immediately updated. Temperature and geopotential are then obtained from the updated value of dry static energy. The dissipation of kinetic energy from vertical diffusion of momentum is calculated explicitly and included in the heating applied to the atmosphere. 


\section{Description of numerical experiments}

For this work we carried out two sets of numerical experiments, one in an aqua-planet framework and the other in a real-planet framework. Since aqua-planet framework is relatively simpler in comparison to real planet, understanding of the underlying mechanism is often easier. Finally, to see how the aqua-planet results translate to full GCM, integrations were performed in actual-planet framework. For all the experiments, semi-Lagrangian dynamical core, $128 \times 64$ horizontal resolution, 26 vertical levels, and $60 \mathrm{~min}$ time step size were used.

\subsection{Aqua-planet integrations}

In the aqua-planet configuration all the land points are replaced by ocean points such that the surface drag coefficients, albedo, and evaporation characteristics are homogeneous over the globe. A further simplification was obtained by fixing the solar declination. Solar insolation was fixed to be same as on 21 March, which puts the sun overhead at the equator. Additionally this produces another desirable simplification by providing approximate hemispheric symmetry of insolation forcing. The experiments have been performed with a zonally symmetric SST profile as boundary condition. The distribution of SST used in the simulation is given in Eq. (1) (similar to the control SST of Neale and Hoskins, 2000).

$T_{\mathrm{S}}(\lambda, \phi)=\begin{array}{lc}27\left[1-\sin ^{2}(3 \phi / 2)\right]^{\circ} \mathrm{C}:-\pi / 3<\phi<\pi / 3 \\ 0{ }^{\circ} \mathrm{C}: & \text { Otherwise }\end{array}$

Where, $T_{\mathrm{S}}=$ Sea Surface Temperature $\left({ }^{\circ} \mathrm{C}\right), \lambda=$ Longitude, $\phi=$ Latitude.

A set of integrations was performed with various values of TAU, ranging from $1 \mathrm{~h}$ to infinity. The initial condition for all simulations was from a previous aqua-planet simulation. All the integrations were performed for 18 months and the last 12 months were used for analysis.

\subsection{Actual-planet integrations}

This framework uses actual land-ocean distribution with topography, observed sea surface temperature and seasonal cycle of solar radiation. Two 10-year (1979 to 1988) simulations were performed with observed SST (Reynolds et al., 2002; Rayner et al., 2003), one with TAU $=1 \mathrm{~h}$ and another with TAU $=8 \mathrm{~h}$. The initial condition used was generated for 1 January 1979. Soil moisture and snow cover were computed by the model. Supplementary information about the numerical experiments is given in the respective places in the following section.

Comparisons with observations were avoided for the aquaplanet analysis, since it doesn't represent the actual terrestrial conditions. However, the results from the actual-planet simulations were compared with the observed data (CMAP rain-

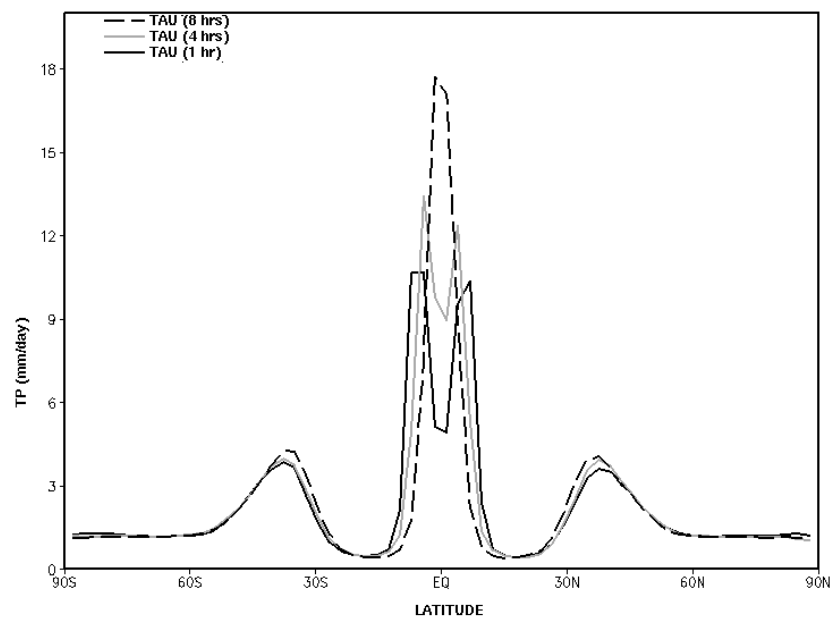

Fig. 1. Zonal averaged time mean total precipitation (TP) with three different TAUs, i.e. TAU $(1 \mathrm{~h})$, TAU $(4 \mathrm{~h})$, and TAU $(8 \mathrm{~h})$. TAU stands for convective relaxation time scale.

fall and TRMM rainfall) for the evaluation, verification, and performance testing.

\section{Results of numerical experiments}

\subsection{Partitioning between precipitation components}

The surface reaching precipitation in CAM3 comprises of three components, namely, deep convective (DCP), shallow convective (SCP), and large-scale precipitation (LSP). The sum of these three components is referred to as the total precipitation (TP). Figure 1 shows the zonally averaged time mean total precipitation for TAU $=1 \mathrm{~h}, \mathrm{TAU}=4 \mathrm{~h}$, and $\mathrm{TAU}=8 \mathrm{~h}$. The impact is noticed mainly within $12.5^{\circ} \mathrm{S}$ to $12.5^{\circ} \mathrm{N}$. Hence, this region is chosen for all further analysis.

In Fig. 2, the time mean area averaged $\left(0^{\circ} \mathrm{E}\right.$ to $360^{\circ} \mathrm{E}$ and $12.5^{\circ} \mathrm{S}$ to $12.5^{\circ} \mathrm{N}$ ) precipitation, and its various components are shown as a function of TAU. Since the maximum permitted time step size for stable integration for the resolution used is $1 \mathrm{~h}$, we could not use a TAU lower than this value, hence the lowest TAU shown in the figure is $1 \mathrm{~h}$. The highest TAU is $\infty$ (infinity), which is the case when deep convective scheme is switched off. From Fig. 2 the following important points emerge: (1) total precipitation is by and large unchanged, (2) DCP, SCP, and LSP show two regimes of response, one for TAU up to $\sim 2 \mathrm{~h}$, where there is no change in their magnitudes, the other for TAU greater than $\sim 2 \mathrm{~h}$, where they show monotonic changes, (3) beyond $2 \mathrm{~h}$, with increase of TAU, DCP decreases, but SCP and LSP increase. So, the invariance in TP is because of the compensation between its components. The compensation primarily occurs between DCP and SCP. Although, LSP shows a steady response, it is one order of magnitude smaller than the other two components. 


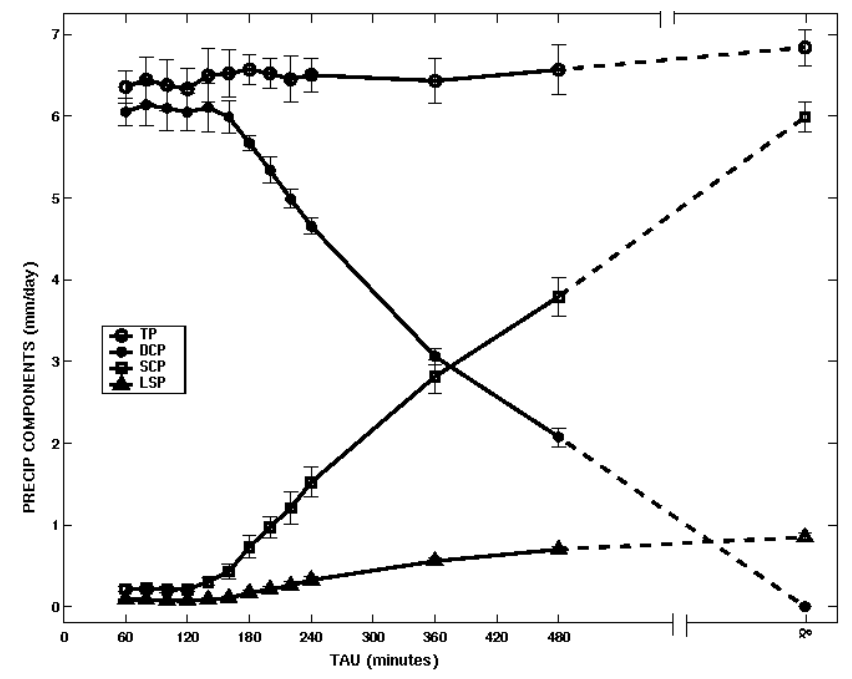

Fig. 2. Area averaged, time mean total precipitation (TP) and its various components (DCP, SCP and, LSP) versus TAU for the region $\left(0^{\circ} \mathrm{E}\right.$ to $360^{\circ} \mathrm{E}$ and $12.5^{\circ} \mathrm{S}$ to $\left.12.5^{\circ} \mathrm{N}\right)$. Points showed adjacent to the right margin represent TAU $=\infty$. The error bars show the respective standard deviation in time about the time mean values. Notations: TP for total precipitation, DCP for deep convective precipitation, SCP for shallow convective precipitation, and LSP for large-scale precipitation (also called as stratiform precipitation).

\subsection{Computation of deep convective precipitation}

The closure for the ZM scheme is based on the budget equation for CAPE. This budget equation may be written as:

$\partial A / \partial t=-M_{\mathrm{b}} F+G$

Where, $A$ represents CAPE, $G$ represents the large-scale production of CAPE by the grid scale dynamics, and $-M_{\mathrm{b}} F$ represents the sub-grid scale CAPE consumption by the parameterized deep convection. $M_{\mathrm{b}}$ represents the cloud base mass flux, and $F$ represents the rate at which cumulus clouds consume CAPE per unit cloud base mass flux. The closure used in the scheme, in CAM3, is a diagnostic closure condition, which is as follows:

$M_{\mathrm{b}}=A / \tau F$

where, $\tau$ is the convective relaxation time scale. This closure assumes that CAPE is consumed at an exponential rate $(1 / \tau)$ by cumulus convection. This may be seen by substituting Eq. (3) in Eq. (2), which will give Eq. (4).

$\partial A / \partial t=-A / \tau+G$

So, if at $t=0$, CAPE is $A_{0}$, in the absence of large-scale CAPE generation, the solution will be, $A=A_{0} \exp (-t / \tau)$, for $t>0$. Hence, when the relaxation time scale (hereafter will be referred as TAU) is increased, it will reduce the magnitude of cloud base mass flux. This in turn determines the updraft mass flux at every level of the model, by taking the entrainment and detrainment rate into consideration. Eventually, updraft mass flux along with cloud liquid water determines the DCP production at every model level, as in Eq. (5).

$[\mathrm{DCP}]_{i}=C 0 \cdot\left[M_{\mathrm{u}}\right]_{i} \cdot[L]_{\mathrm{i}}$

where, $C 0$ is the DCP production efficiency parameter, $M_{\mathrm{u}}$ is the updraft mass flux, and $L$ is the cloud liquid water at the $i$-th level. The vertical integral of $[\mathrm{DCP}]_{\mathrm{i}}$ over all the model levels, gives the surface reaching DCP.

To understand, why change in TAU up to $2 \mathrm{~h}$, there was no impact, 3 -cases were chosen (namely, TAU $(1 \mathrm{~h})$, TAU $(2 \mathrm{~h})$, and TAU $(8 \mathrm{~h})$ ) for a more detailed investigation. Figure 3 shows surface reaching DCP, vertical structure of DCP production rate, updraft mass flux, and cloud liquid water. The top panel of the figure shows the comparison between TAU $(1 \mathrm{~h})$ and TAU $(2 \mathrm{~h})$ and the bottom panel for TAU $(1 \mathrm{~h})$ and TAU $(8 \mathrm{~h})$. Figure $3 \mathrm{a} 3$ shows that updraft mass flux in TAU ( $1 \mathrm{~h}$ ) and TAU ( $2 \mathrm{~h})$ ) is almost same at all the model levels, except in the layers adjacent to the surface. Figure 3a4 shows the cloud liquid water is almost same in both the cases. Hence, as expected, the DCP production rate (Fig. 3a2) is also found to be same at all the model levels and so is the surface reaching DCP (Fig. 3a1).

Bottom panel shows that updraft mass flux is lower for TAU $(8 \mathrm{~h})$ than TAU $(1 \mathrm{~h})$. The cloud liquid water is found to be higher in TAU $(8 \mathrm{~h})$. The effect of reduction in updraft mass flux on the production of DCP outweighs that caused by the increase in cloud liquid water and thus resulting in a lower value of DCP production. Figure 4 shows the entrainment and detrainment rates for TAU $(1 \mathrm{~h})$, TAU $(2 \mathrm{~h})$ and TAU ( $8 \mathrm{~h}$ ). Figure $4 \mathrm{a} 3$ and (b3) show the net lateral mixing due to the combined effect of entrainment and detrainment. The net lateral mixing is found to be negative in most of the levels in TAU $(1 \mathrm{~h})$ and TAU $(2 \mathrm{~h})$, which is the reason behind the decrease in updraft mass flux with height in these simulations. Whereas in TAU $(8 \mathrm{~h})$, the net lateral mixing is nearly zero from the surface up to $300 \mathrm{hPa}$. This is why, the updraft mass flux does not show an appreciable change with height.

The zonally averaged time mean, cloud base mass flux, CAPE, and CAPE consumption rate per unit cloud base mass flux, are shown in Fig. 5. It is noticed that, an increase in TAU results in a decrease in the cloud base mass flux, increase of CAPE, and also increase of CAPE consumption rate per unit cloud base mass flux. From Eq. (3), it was expected that, increase of TAU will lead to decrease in cloud base mass flux, which is confirmed from Fig. 5a1 and b1. When TAU is less than $2 \mathrm{~h}$, the reduction in the updraft mass loss due to lateral mixing is lower and hence compensates for the decrease in cloud base mass flux. Hence there is no impact on DCP when TAU is increased till $2 \mathrm{~h}$. But, for TAU greater than $2 \mathrm{~h}$, the reduction of cloud base mass flux is more than the reduction of lateral mixing, which is why DCP decreases after $2 \mathrm{~h}$. 
COMPARISON OF TAU (1 hr) and TAU (2 hrs)
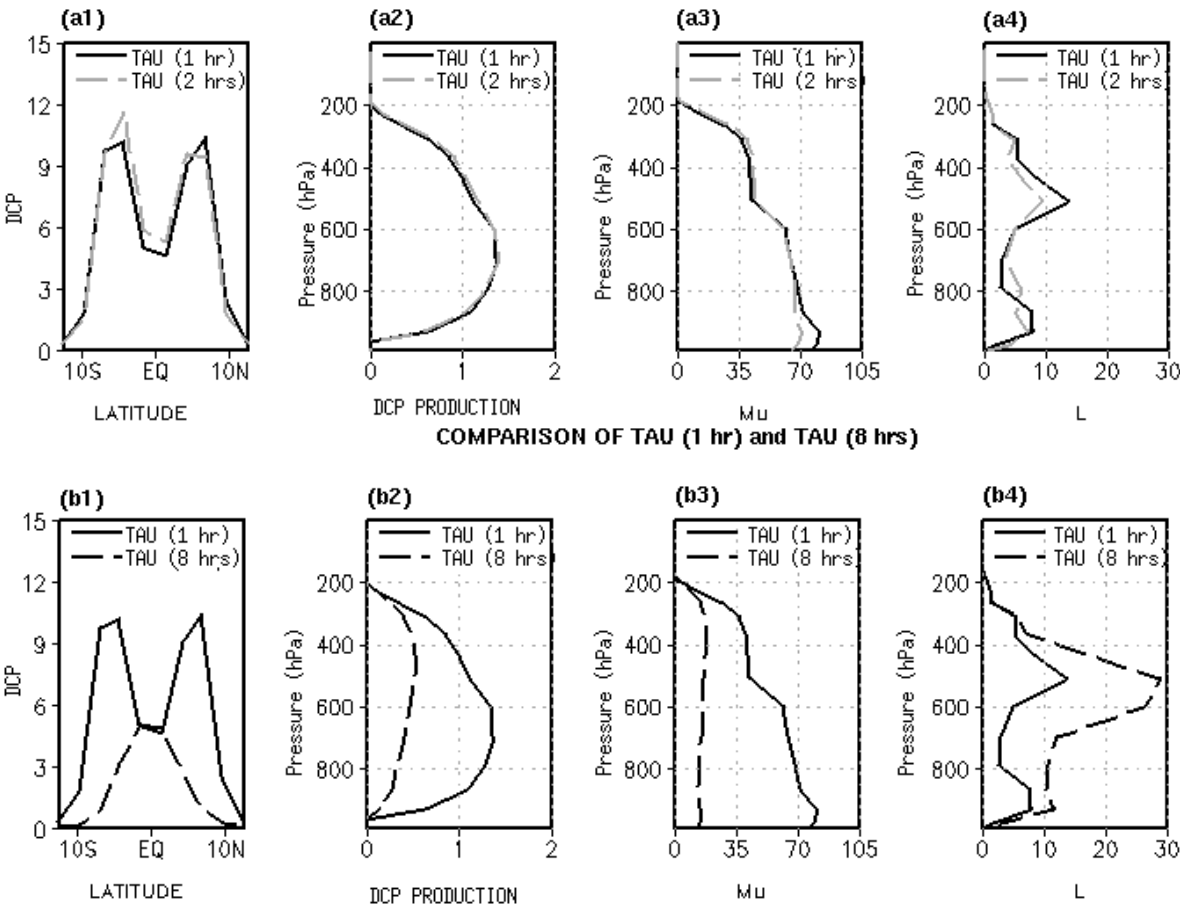

Fig. 3. Top panel shows the comparison of TAU $(1 \mathrm{~h})$ and TAU $(2 \mathrm{~h})$, and bottom panel shows the comparison of TAU ( $1 \mathrm{~h})$ and TAU $(8 \mathrm{~h})$. (a1) and (b1) show the zonal averaged time mean surface reaching DCP (mm/day), (a2) and (b2) show the vertical profile of area $\left(0^{\circ} \mathrm{E}\right.$ to $360^{\circ} \mathrm{E}$ and $12.5^{\circ} \mathrm{S}$ to $\left.12.5^{\circ} \mathrm{N}\right)$ averaged DCP production $(\mathrm{kg} / \mathrm{kg} / \mathrm{day}),(\mathbf{a 3})$ and $(\mathbf{b 3})$ show the vertical profile of area $\left(0^{\circ} \mathrm{E}\right.$ to $360^{\circ} \mathrm{E}$ and $12.5^{\circ} \mathrm{S}$ to $\left.12.5^{\circ} \mathrm{N}\right)$ averaged updraft mass flux (mb/day), and (a4) and (b4) show the vertical profile of area $\left(0^{\circ} \mathrm{E}\right.$ to $360^{\circ} \mathrm{E}$ and $12.5^{\circ} \mathrm{S}$ to $\left.12.5^{\circ} \mathrm{N}\right)$ averaged cloud water $\left(\right.$ gram $\left./ \mathrm{m}^{2}\right)$.

\subsection{Shallow convective precipitation and large scale precipitation}

Figure 6 shows the impact of TAU on shallow convective precipitation (SCP) and large-scale precipitation (LSP). SCP and LSP are found to be more when TAU is $8 \mathrm{~h}$. Since, there is considerable difference in SCP and LSP in the region $7^{\circ} \mathrm{S}$ to $7^{\circ} \mathrm{N}$ (see a1 and b1), our analysis will now be confined to this region. When TAU is $1 \mathrm{~h}, \mathrm{SCP}$ and LSP production was primarily confined to the upper troposphere (see Fig. $6 \mathrm{a} 2$ and b2). When TAU is $8 \mathrm{~h}$, a significant enhancement of SCP and LSP is noticed in lower and mid troposphere.

Figure 7 shows the vertical profiles of moist static energy (MSE), relative humidity, liquid condensate and ice condensate from TAU $(1 \mathrm{~h})$ and TAU $(8 \mathrm{~h})$. When TAU is $8 \mathrm{~h}$, the MSE is found to be higher in the lower troposphere and cloud liquid water is higher in lower as well as mid troposphere. Hence, the enhancement of SCP in the lower troposphere is due to increase of both MSE and cloud liquid water. However, increase in SCP in the mid troposphere is due to the increase of cloud liquid water alone, as there is not much difference in MSE. Figure 7b shows that RH is more in the lower and upper troposphere, when TAU is higher. As can be seen from Fig. 7c, the liquid condensate is found to be more in the lower and middle troposphere, when TAU is $8 \mathrm{~h}$, whereas, ice condensate is not significantly different (Fig. 7d). Hence, higher value of LSP in the lower troposphere is due to the increase in RH when TAU is $8 \mathrm{~h}$, whereas, in the middle troposphere, the increase in LSP is caused by the increase in liquid condensate.

It is noticed in Fig. 6 that there is no considerable difference between TAU $(1 \mathrm{~h})$ and TAU $(2 \mathrm{~h})$. This is due to the fact that, DCP was unchanged up to $2 \mathrm{~h}$ because of the compensation between the decrease of cloud base mass flux and increase of the lateral mixing.

\subsection{Temperature and moisture}

\subsubsection{Vertical structure}

Figure 8 shows the difference in Temperature and specific humidity between TAU values of $8 \mathrm{~h}$ and $1 \mathrm{~h}$. The temperature is higher below $550 \mathrm{hPa}$, and above $250 \mathrm{hPa}$, when TAU is $8 \mathrm{~h}$. Between $550 \mathrm{hPa}$ and $250 \mathrm{hPa}$, the temperature is found to be lower than that in TAU $(1 \mathrm{~h})$. Similarly, specific humidity is found to be higher when TAU $(8 \mathrm{~h})$, from the surface up to $600 \mathrm{hPa}$, and lower between $600 \mathrm{hPa}$ and $350 \mathrm{hPa}$. Hence, both temperature and specific humidity, are found to 
COMPARISON OF TAU (1 hr) and TAU (2 hrs)
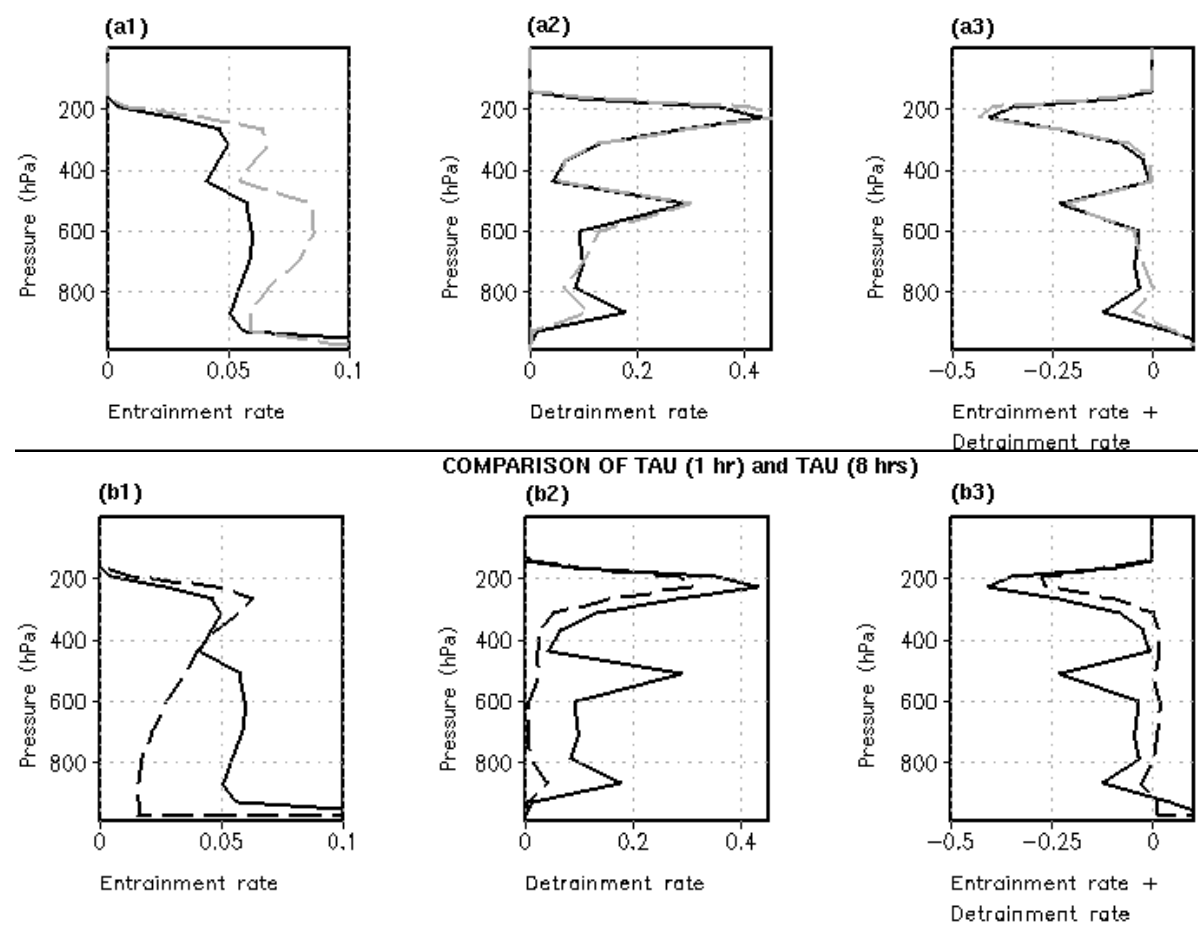

Fig. 4. Top panel shows the comparison of TAU $(1 \mathrm{~h})$ and TAU $(2 \mathrm{~h})$, and bottom panel shows the comparison of TAU (1 h) and TAU ( $8 \mathrm{~h})$. (a1) and (b1) show the vertical profile of area $\left(0^{\circ} \mathrm{E}\right.$ to $360^{\circ} \mathrm{E}$ and $12.5^{\circ} \mathrm{S}$ to $\left.12.5^{\circ} \mathrm{N}\right)$ averaged updraft mass entrainment rate (per day), (a2) and (b2) show the vertical profile of area $\left(0^{\circ} \mathrm{E}\right.$ to $360^{\circ} \mathrm{E}$ and $12.5^{\circ} \mathrm{S}$ to $12.5^{\circ} \mathrm{N}$ ) averaged -ve updraft mass detrainment rate, (per day), and (a3) and (b3) show the vertical profile of area $\left(0^{\circ} \mathrm{E}\right.$ to $360^{\circ} \mathrm{E}$ and $12.5^{\circ} \mathrm{S}$ to $\left.12.5^{\circ} \mathrm{N}\right)$ averaged updraft mass entrainment and detrainment rate, (per day).

be responsible for the observed structure of MSE and RH. Similar difference was observed in geopotential height (not shown here), but its contribution to MSE is an order of magnitude less than that contributed by temperature and moisture.

\subsubsection{Heating rates}

The heating rate due to moist and radiative processes are shown in Fig. 9. Top panel shows the heating rate with TAU $(1 \mathrm{~h})$ and TAU $(8 \mathrm{~h})$, while the bottom panel shows the difference between them i.e. [TAU $(8 \mathrm{~h})$ - TAU $(1 \mathrm{~h})$ ]. Figure $9 \mathrm{a} 2$ indicates that, relatively TAU $(8 \mathrm{~h})$ has larger moist heating below $550 \mathrm{hPa}$ and above $250 \mathrm{hPa}$. In between the above two altitudes it is is lesser than that of TAU $(1 \mathrm{~h})$.

However, Radiative processes cause more cooling below $500 \mathrm{hPa}$ and between $350 \mathrm{hPa}$ and $250 \mathrm{hPa}$, and does the reverse at all other model layers. Close comparison of Fig. 9a2 and b2 with Fig. 8a revels that, the moist processes are primarily responsible for the observed temperature structure, discussed above.

\subsubsection{Surface evaporation and large-scale moisture con- vergence}

Figure 10a shows the difference in zonally averaged, time mean, surface evaporation between TAU $(8 \mathrm{~h})$ and TAU $(1 \mathrm{~h})$. Similarly, Fig. 10b shows the difference in the large-scale moisture convergence i.e. (PRECIP - EVP). It is noticed from Fig. 10a that, surface evaporation is more in TAU $(8 \mathrm{~h})$ over $\sim 10^{\circ} \mathrm{S}-10^{\circ} \mathrm{N}$, and beyond $20^{\circ} \mathrm{S} / \mathrm{N}$. However, between $10^{\circ} \mathrm{S} / \mathrm{N}$ to $20^{\circ} \mathrm{S} / \mathrm{N}$ it is lower than that in TAU $(1 \mathrm{~h})$. Moreover, over equatorial belt $\left(5^{\circ} \mathrm{S}-5^{\circ} \mathrm{N}\right)$, the difference is almost zero. Figure $10 \mathrm{~b}$ shows that, over $5^{\circ} \mathrm{S}-5^{\circ} \mathrm{N}$, the largescale moisture convergence in TAU $(8 \mathrm{~h})$ is higher, whereas it is found to be lower in between $5^{\circ} \mathrm{S} / \mathrm{N}$ and $12.5^{\circ} \mathrm{S} / \mathrm{N}$. In Fig. $8 \mathrm{~b}$, it was noticed that, for TAU $(8 \mathrm{~h})$, over $7^{\circ} \mathrm{S}-7^{\circ} \mathrm{N}$, the specific humidity is higher in the atmospheric column except between $600 \mathrm{hPa}$ to $400 \mathrm{hPa}$. For the latitudinal belt between $7^{\circ} \mathrm{S}-7^{\circ} \mathrm{N}$, the higher specific humidity in the atmospheric column is primarily due to increase in the large-scale moisture convergence into this region, and partly due to the local evaporation. Figure 10c1 shows the vertical profile of the lateral moisture transport into this region. Positive values indicate transport into the region, whereas, negative values indicate transport out of the region. Figure 10c2 shows the 
COMPARISON OF TAU (1 hr) and TAU (2 hrs)
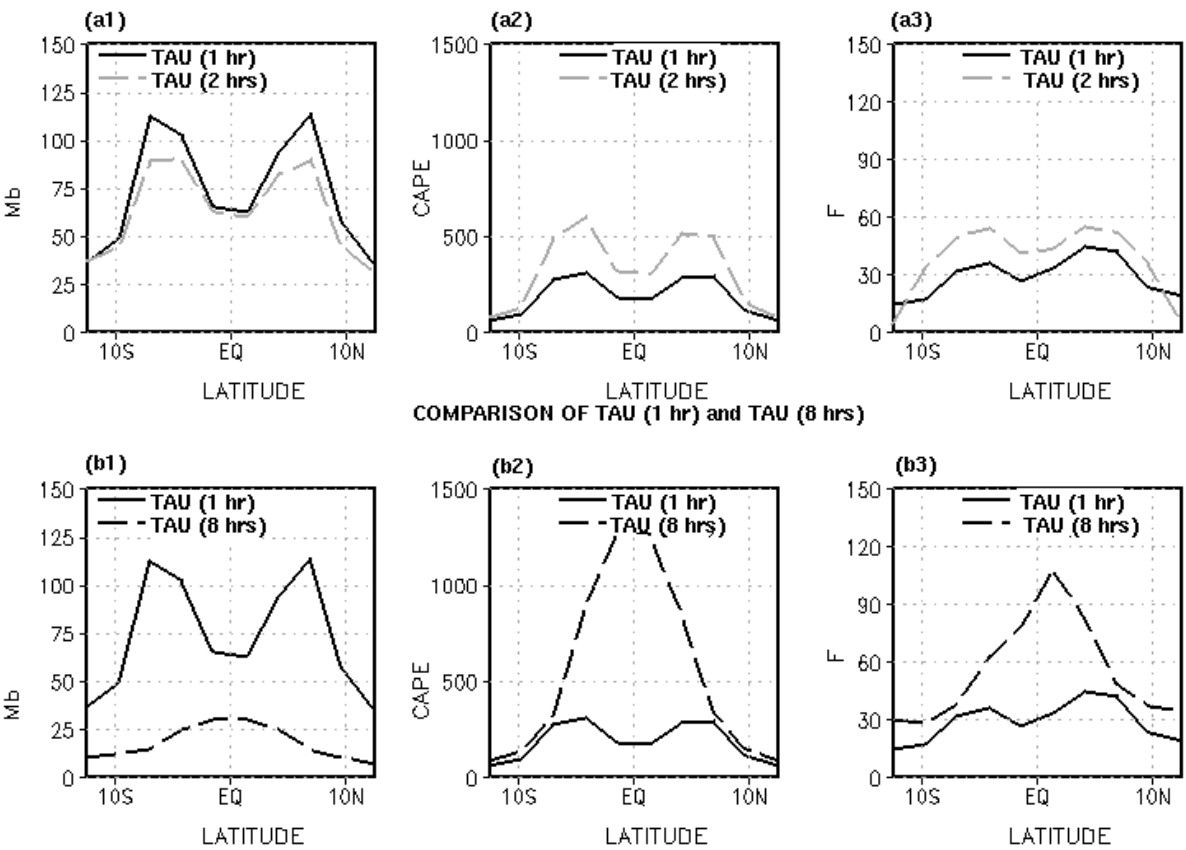

Fig. 5. Zonal averaged time mean quantities. Top panel shows the comparison of TAU ( $1 \mathrm{~h})$ and TAU ( $2 \mathrm{~h})$, and bottom panel shows the comparison of TAU (1 h) and TAU ( $8 \mathrm{~h})$. (a1) and (b1) show the cloud base mass flux (mb/day), (a2) and (b2) show CAPE (J/Kg), (a3) and (b3) show $F$, which is the CAPE consumption rate per unit cloud base mass flux $(\mathrm{J} / \mathrm{Kg} / \mathrm{Mb})$.
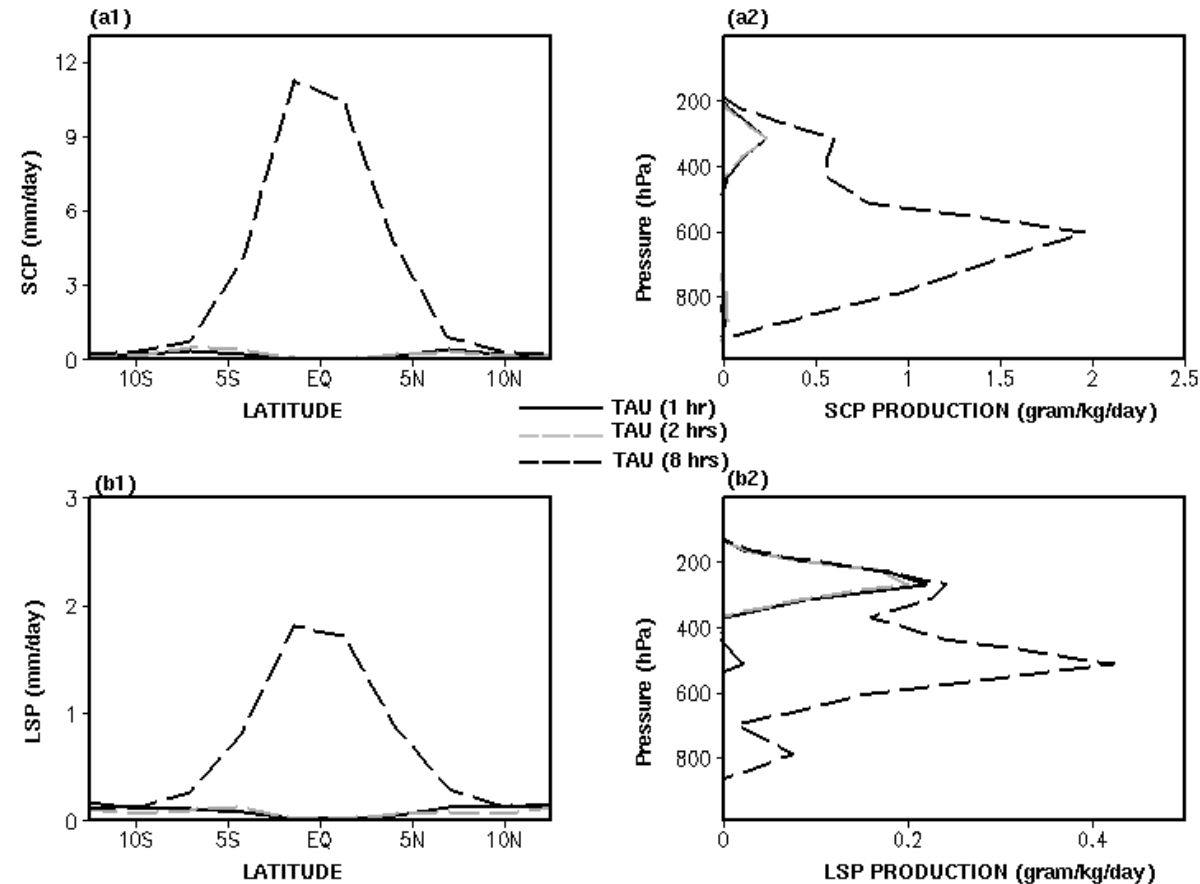

Fig. 6. Time mean quantities with TAU (1 h), TAU (2 h), and TAU ( 8 h). (a1) Zonal averaged SCP, (b1) Zonal averaged LSP, (a2) Vertical distribution of the area averaged SCP production over $0^{\circ} \mathrm{E}$ to $360^{\circ} \mathrm{E}$ and $7^{\circ} \mathrm{S}$ to $7^{\circ} \mathrm{N}$, and (b2) vertical distribution of the area averaged LSP production over $0^{\circ} \mathrm{E}$ to $360^{\circ} \mathrm{E}$ and $7^{\circ} \mathrm{S}$ to $7^{\circ} \mathrm{N}$. 

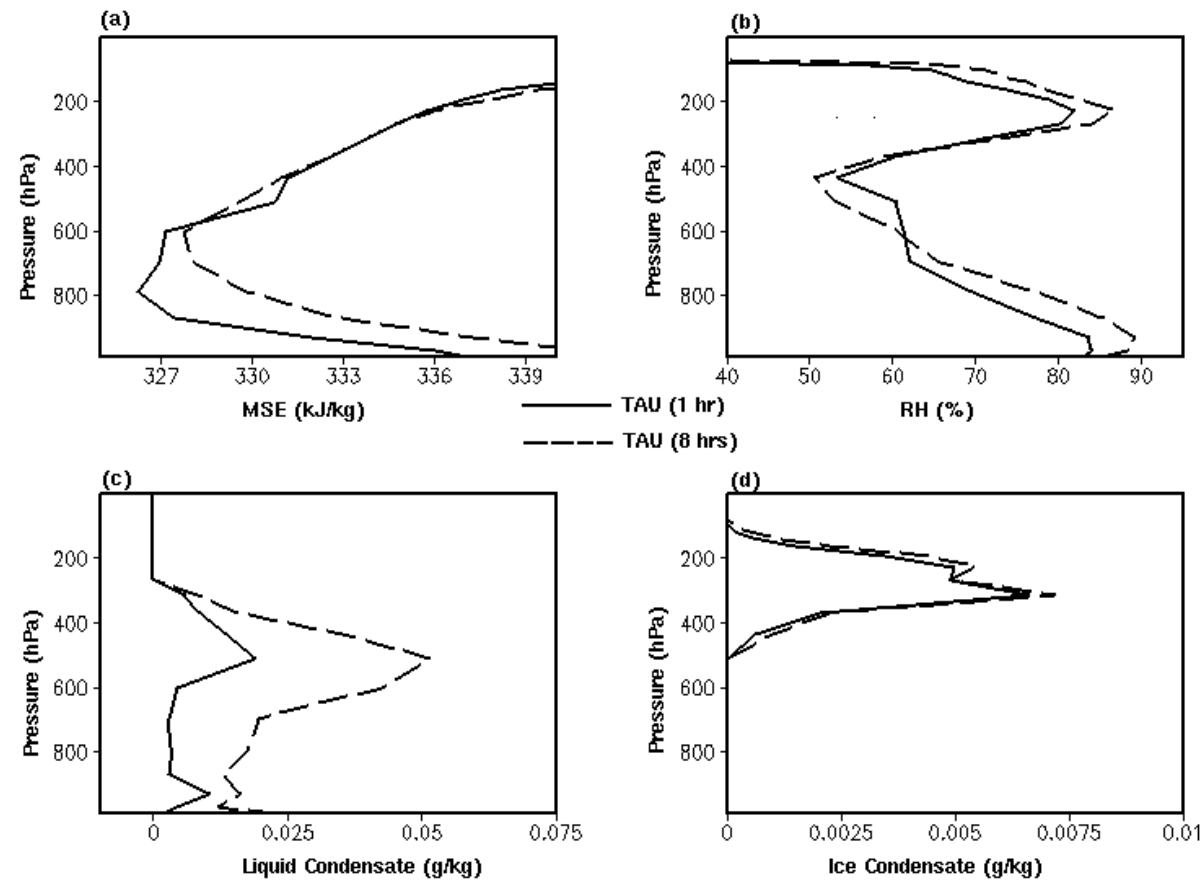

Fig. 7. Vertical structure of the time mean area averaged quantities over $0^{\circ} \mathrm{E}$ to $360^{\circ} \mathrm{E}$ and $7^{\circ} \mathrm{S}$ to $7^{\circ} \mathrm{N}$ with TAU (1 h) and TAU ( $8 \mathrm{~h}$ ). (a) Moist Static Energy (MSE), (b) RH, (c) liquid condensate, and (d) ice condensate.
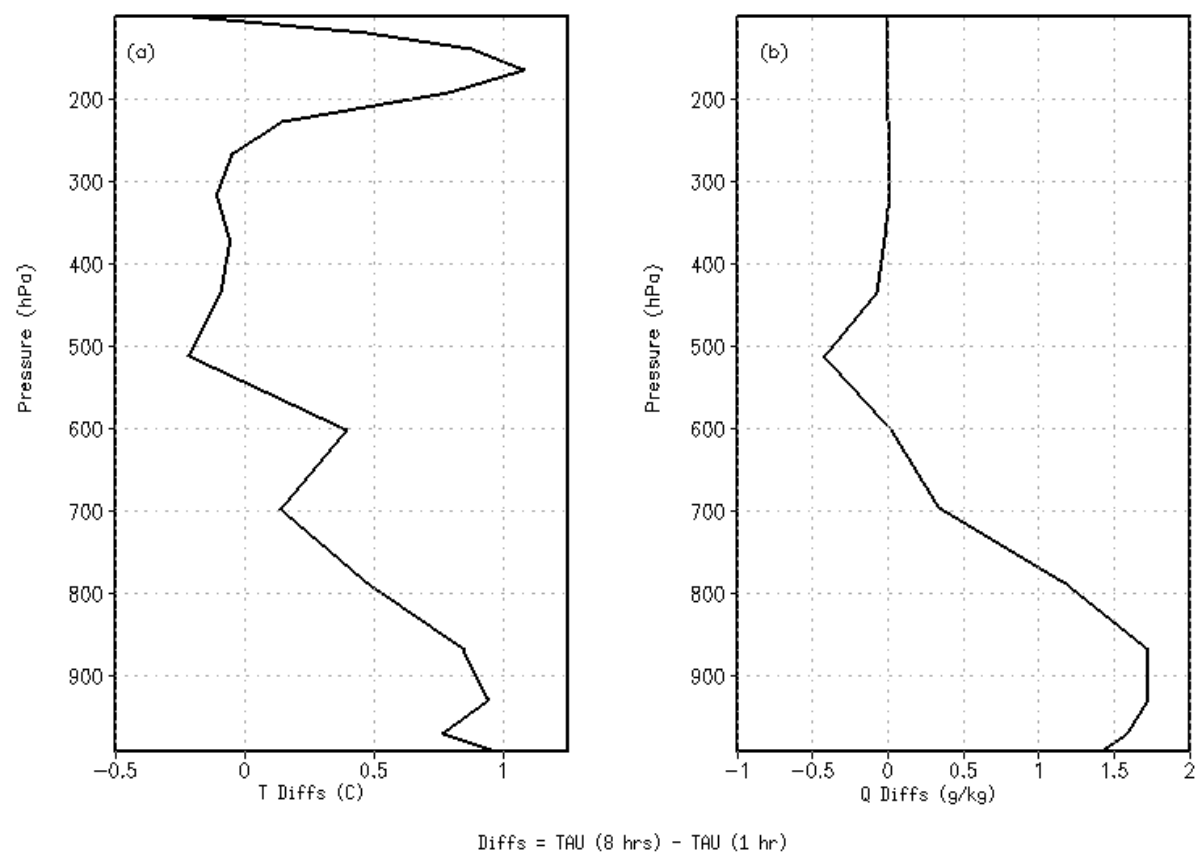

Fig. 8. Vertical structure of the time mean area averaged quantities over $0^{\circ} \mathrm{E}$ to $360^{\circ} \mathrm{E}$ and $7^{\circ} \mathrm{S}$ to $7^{\circ} \mathrm{N}$ with TAU (1 h) and TAU ( $8 \mathrm{~h}$ ). (a) $T$, and (b) $Q$.

difference between them, i.e. [TAU $(8 \mathrm{~h})-$ TAU $(1 \mathrm{~h})$ ]. It can be noticed from the figure that, more amount of moisture is coming into this region in the lower troposphere, for the TAU $(8 \mathrm{~h})$ case. On the other hand, more amount of moisture is also going out from this region in the middle and upper troposphere. This resembles the profile of the specific humidity that was noticed in Fig. 8b. 

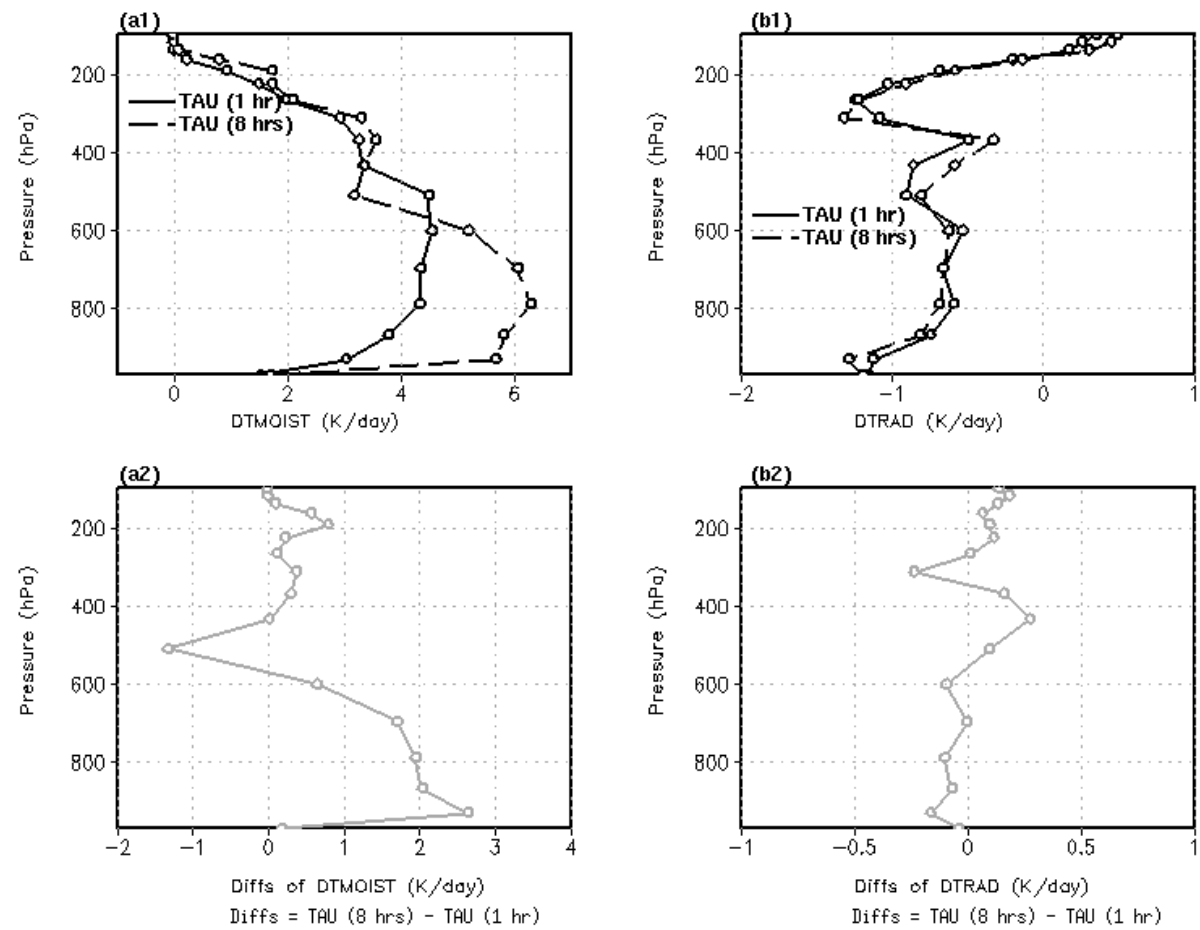

Fig. 9. Top panel shows the vertical structure of the time mean area averaged quantities over $0^{\circ} \mathrm{E}$ to $360^{\circ} \mathrm{E}$ and $7^{\circ} \mathrm{S}$ to $7^{\circ} \mathrm{N}$ with $\mathrm{TAU}$ $(1 \mathrm{~h})$ and TAU $(8 \mathrm{~h})$. (a1) Temperature tendency due to moist processes, (b1) temperature tendency due to radiative processes. Bottom panel shows the differences between TAU $(8 \mathrm{~h})$ and TAU $(1 \mathrm{~h})$.
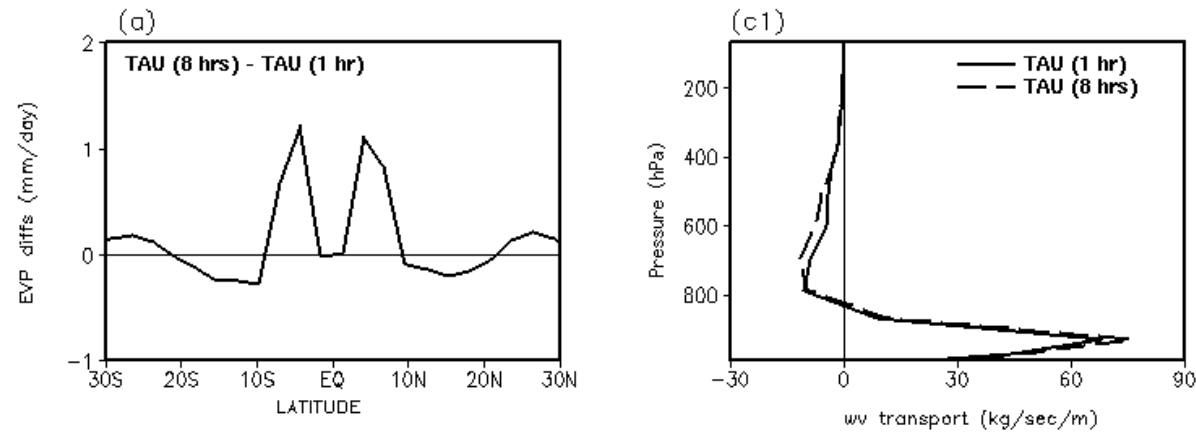

(b)
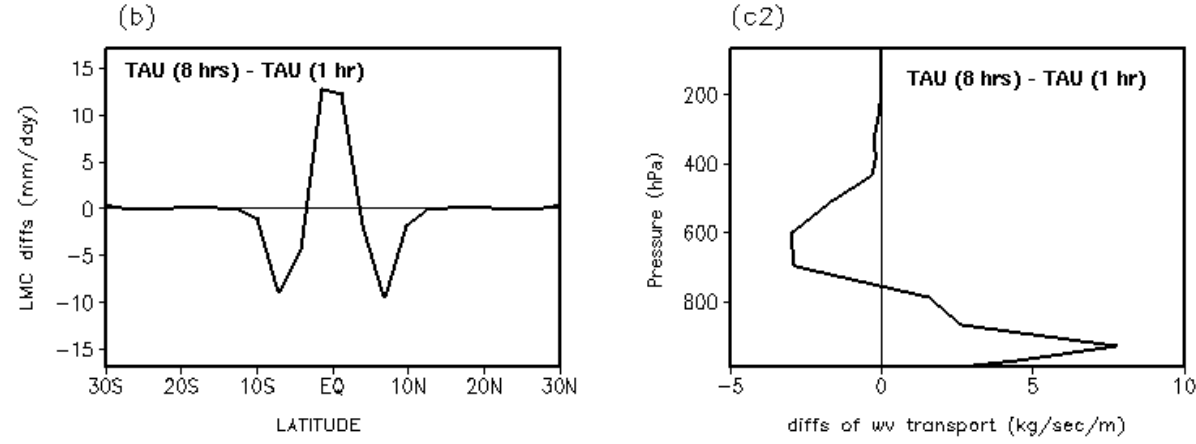

Fig. 10. (a) Difference [TAU $(8 \mathrm{~h})$ - TAU $(1 \mathrm{~h})]$ of the zonally averaged time mean surface evaporation in mm/day. (b) Difference [TAU ( $8 \mathrm{~h})$ - TAU (1 h)] of the zonally averaged time mean large-scale moisture convergence. (c1) Vertical profile of the zonally averaged time mean moisture transport into the region $7^{\circ} \mathrm{S}-7^{\circ} \mathrm{N},(\mathrm{kg} / \mathrm{m} / \mathrm{s})$. (c2) Vertical profile of the difference [TAU $\left.(8 \mathrm{~h})-\mathrm{TAU}(1 \mathrm{~h})\right]$ of the zonal averaged time mean moisture transport into the region $7^{\circ} \mathrm{S}-7^{\circ} \mathrm{N},(\mathrm{kg} / \mathrm{m} / \mathrm{s})$. 

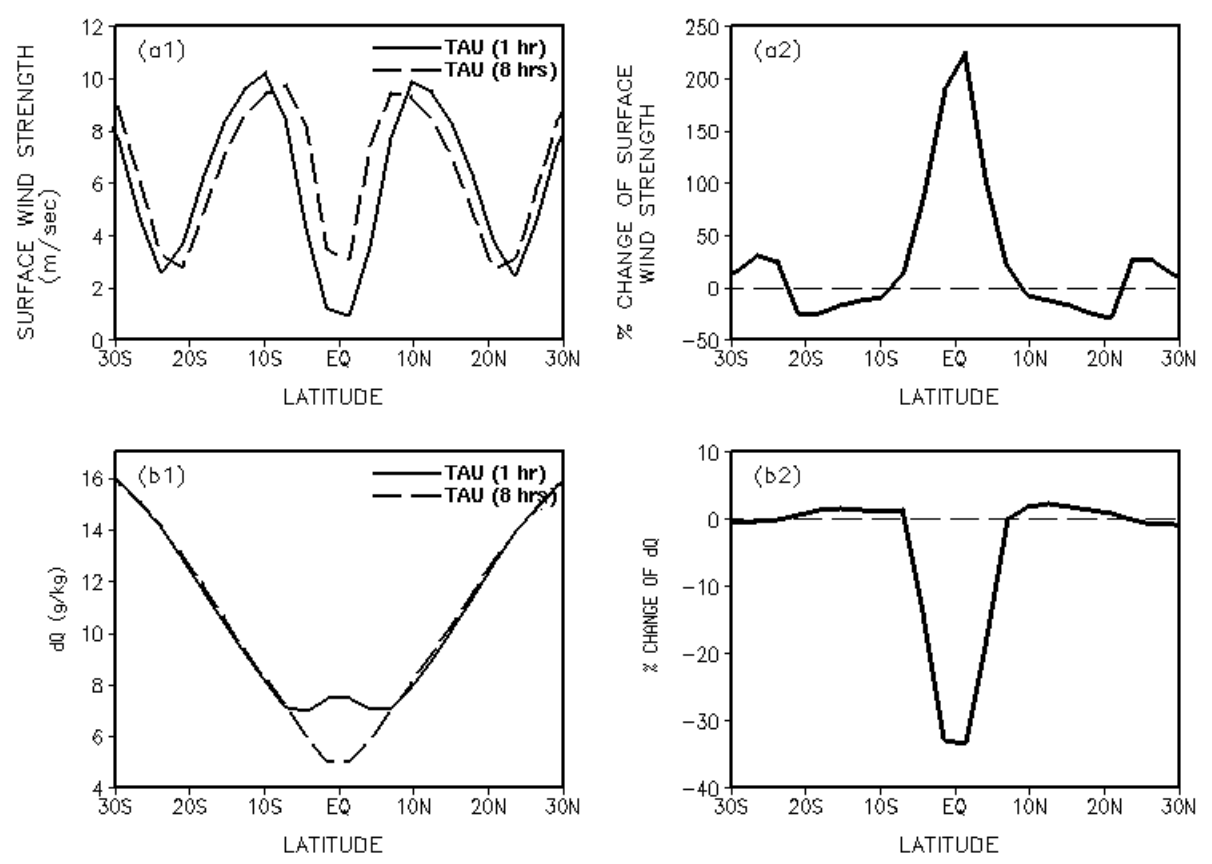

Fig. 11. Zonally averaged time mean quantity with TAU $(1 \mathrm{~h})$, and TAU $(8 \mathrm{~h})$, (a1) wind magnitude at lowest model level (m/s), (a2) percentage change of magnitude of wind at the lowest model level of TAU $(8 \mathrm{~h})$ with respect to TAU $(1 \mathrm{~h})$, (b1) dq at lowest model level (g/kg), (b2) percentage change of dq for TAU $(8 \mathrm{~h})$ with respect to TAU $(1 \mathrm{~h})$.

Notation: Percentage change of TAU $(8 \mathrm{~h})$ with respect to TAU $(1 \mathrm{~h})=[(\mathrm{TAU}(8 \mathrm{~h})-\mathrm{TAU}(1 \mathrm{~h})) / \mathrm{TAU}(1 \mathrm{~h})\} \cdot 100, \mathrm{dq}=Q_{\mathrm{S}}\left(T_{\mathrm{S}}\right)-\mathrm{QA}$.

\subsubsection{Surface level wind strength and moisture deficit}

Figure 11a1 shows the surface level wind strength, and panel (b1) shows the moisture deficit at the 1st model level. In Fig. $11 \mathrm{a} 2$ and b2, the corresponding percentage change is shown i.e., [\{TAU $(8 \mathrm{~h})$ - TAU $(1 \mathrm{~h})\} /$ TAU $(1 \mathrm{~h})] \cdot 100$. Wind strength in TAU $(8 \mathrm{~h})$ is found to be higher over $10^{\circ} \mathrm{S}-10^{\circ} \mathrm{N}$ and beyond $20^{\circ} \mathrm{S} / \mathrm{N}$, and lower over $10^{\circ} \mathrm{S} / \mathrm{N}$ and $20^{\circ} \mathrm{S} / \mathrm{N}$. On the other hand, the moisture deficit at the 1 st model level, is found to be lower with TAU $(8 \mathrm{~h})$, between $10^{\circ} \mathrm{S}-10^{\circ} \mathrm{N}$. A closer look at Fig. 10a and Fig. 11a2 and b2, reveals that the observed surface evaporation profile is due to the combined effect of wind strength and moisture deficit at the 1st model level (dq). However, the surface wind strength is found to be the primary cause, for the enhancement of evaporation over $10^{\circ} \mathrm{S}-10^{\circ} \mathrm{N}$, which in turn gets transported into $7^{\circ} \mathrm{S}-7^{\circ} \mathrm{N}$, by the lateral moisture convergence and causes higher specific humidity in that region.

\subsection{Large scale circulation}

\subsubsection{Meridional cell}

Time mean, zonally averaged, meridional circulation is shown in Fig. 12a and b, respectively for TAU $(1 \mathrm{~h})$ and TAU $(8 \mathrm{~h})$. In the background of these plots, zonally averaged time mean total surface precipitation is also shown. The position of the ITCZ and position of the strongest ascent are found to coincide at the same latitudes. The notable differences between the two cases i.e., TAU $(1 \mathrm{~h})$ and TAU $(8 \mathrm{~h})$ are the following: in TAU $(1 \mathrm{~h})$ the circulation over the equatorial belt is weak, whereas in TAU $(8 \mathrm{~h})$ circulation over the same region becomes strong. The rising limb of Hadley cell shifts towards the equator in TAU $(8 \mathrm{~h})$, associated with strong surface winds over the equatorial belts. This strengthening of the circulation, in turn, leads to an increase in the moisture convergence into the equatorial region.

\subsubsection{Vertical velocity}

Zonally averaged time mean vertical pressure velocity (omega) is shown in Fig. 13a1 and a2 for TAU (1 h) and TAU ( $8 \mathrm{~h}$ ), respectively. A negative value of omega is associated with ascending motion, which is indicated by the background gray shading. It is observed that the ascending limb is more confined to the equator in TAU $(8 \mathrm{~h})$. The latitudinal positions of the maximum omega are noticed over the corresponding locations of the ITCZs/ITCZ, i.e. $\pm 7^{\circ}$ and $0^{\circ}$ in TAU $(1 \mathrm{~h})$ and TAU $(8 \mathrm{~h})$, respectively. The notable difference is the vertical position of the maximum omega. In TAU $(1 \mathrm{~h})$ there are two maxima in the vertical. The primary maximum occurs in the upper troposphere at $300 \mathrm{hPa}$, whereas, the secondary maximum occurs at $850 \mathrm{hPa}$, both being away from the equator. In the case of TAU $(8 \mathrm{~h})$, the maximum omega occurs at lower troposphere i.e. around $800 \mathrm{hPa}$, and is found to be over the equator. Another notable aspect is 

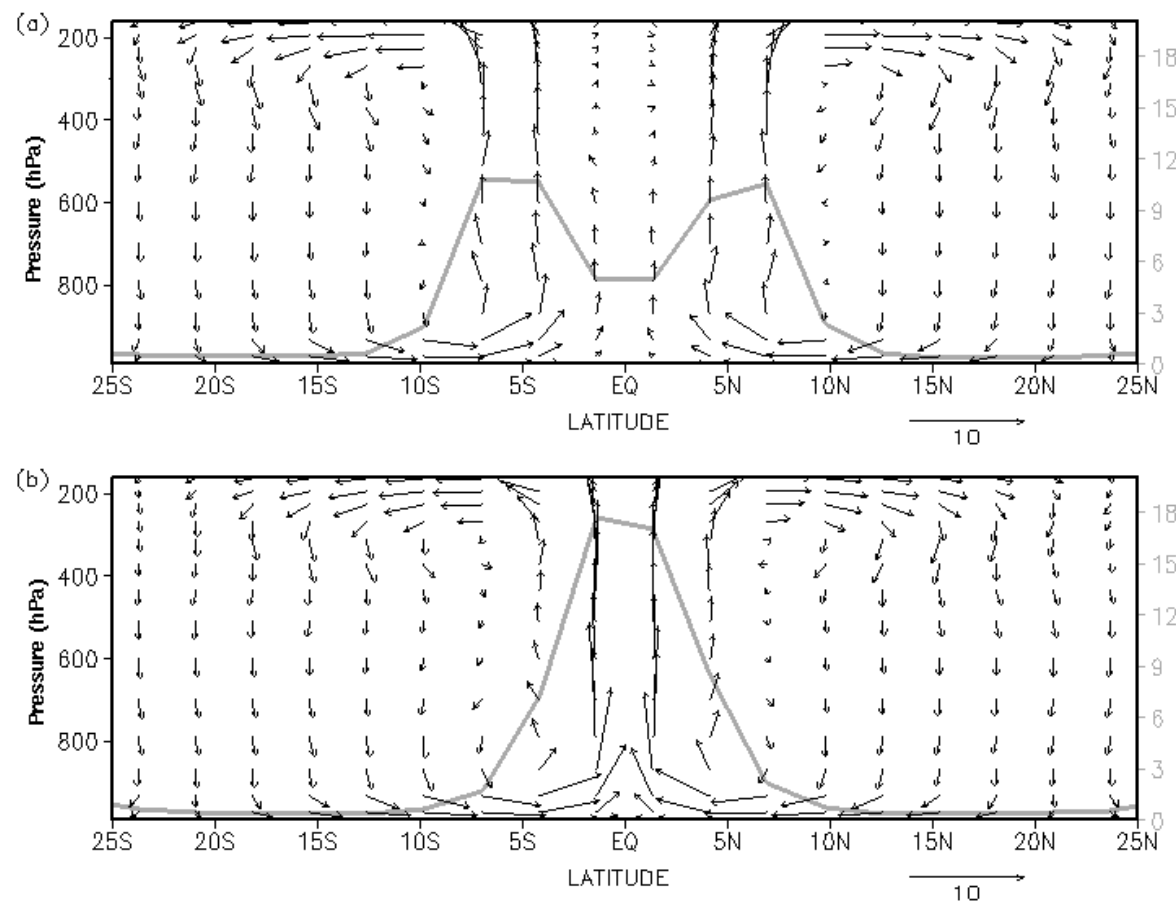

Fig. 12. Zonally averaged time mean meridional circulation (vector arrows: v; 50xw) and total precipitation (grey line) for (a) TAU (1 h), and (b) TAU ( $8 \mathrm{~h})$.
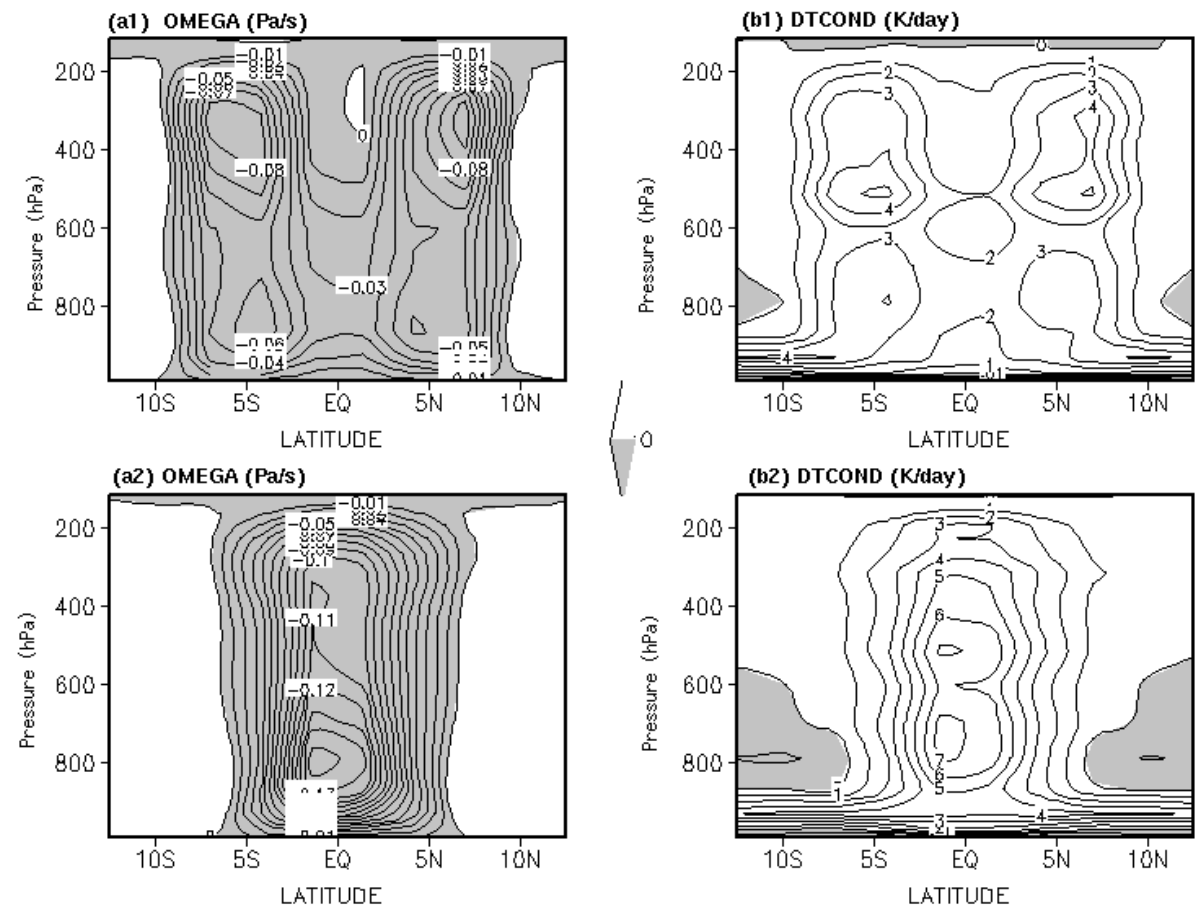

Fig. 13. Zonally averaged time mean quantities with TAU (1 h) and TAU $(8 \mathrm{~h})$. (a1) Pressure vertical velocity with TAU (1 h), (a2) pressure vertical velocity with TAU $(8 \mathrm{~h})$. (b1) Heating rate due to all the moist processes with TAU $(1 \mathrm{~h})$, and (b2) heating rate due to all the moist processes with TAU $(8 \mathrm{~h})$. Gray shading indicates the negative values. Negative omega means ascending motion, and negative heating rate means cooling due to evaporation of precipitating precipitation and melting of the precipitating ice. Contours are labeled inside the plots. 

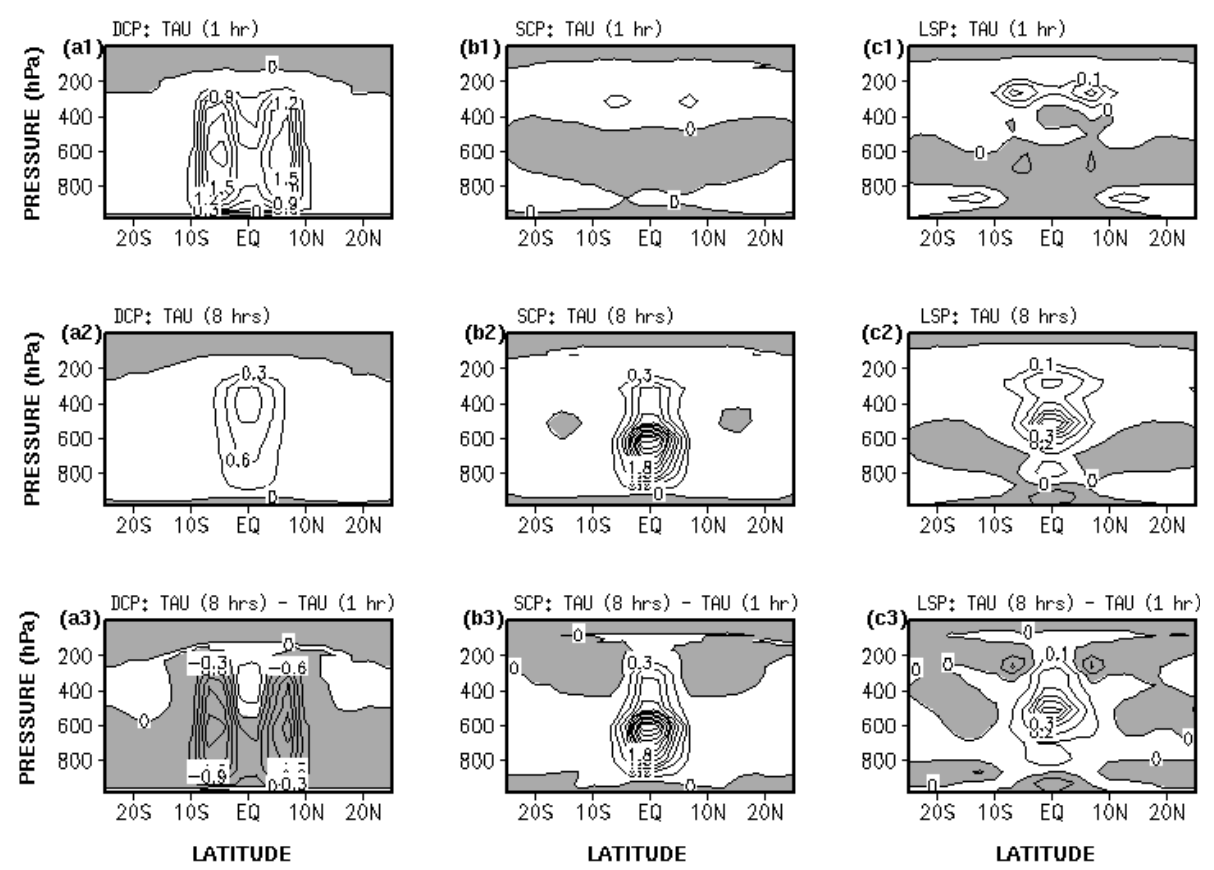

Fig. 14. Vertical distribution of the net precipitation production from each component of the total precipitation. Zonally averaged time mean values are shown. Unit of all the quantities are same and in $\mathrm{kg} / \mathrm{kg} / \mathrm{day}$. Notation: DCP represents the deep convective precipitation, which is computed by deep convective precipitation scheme. SCP represents the shallow convective precipitation, which is computed by shallow convective precipitation scheme. LSP represents the large-scale precipitation, which is computed by large-scale precipitation scheme. Shading indicates (-)ve values i.e. re-evaporation of precipitating precipitation and cloud liquid water.
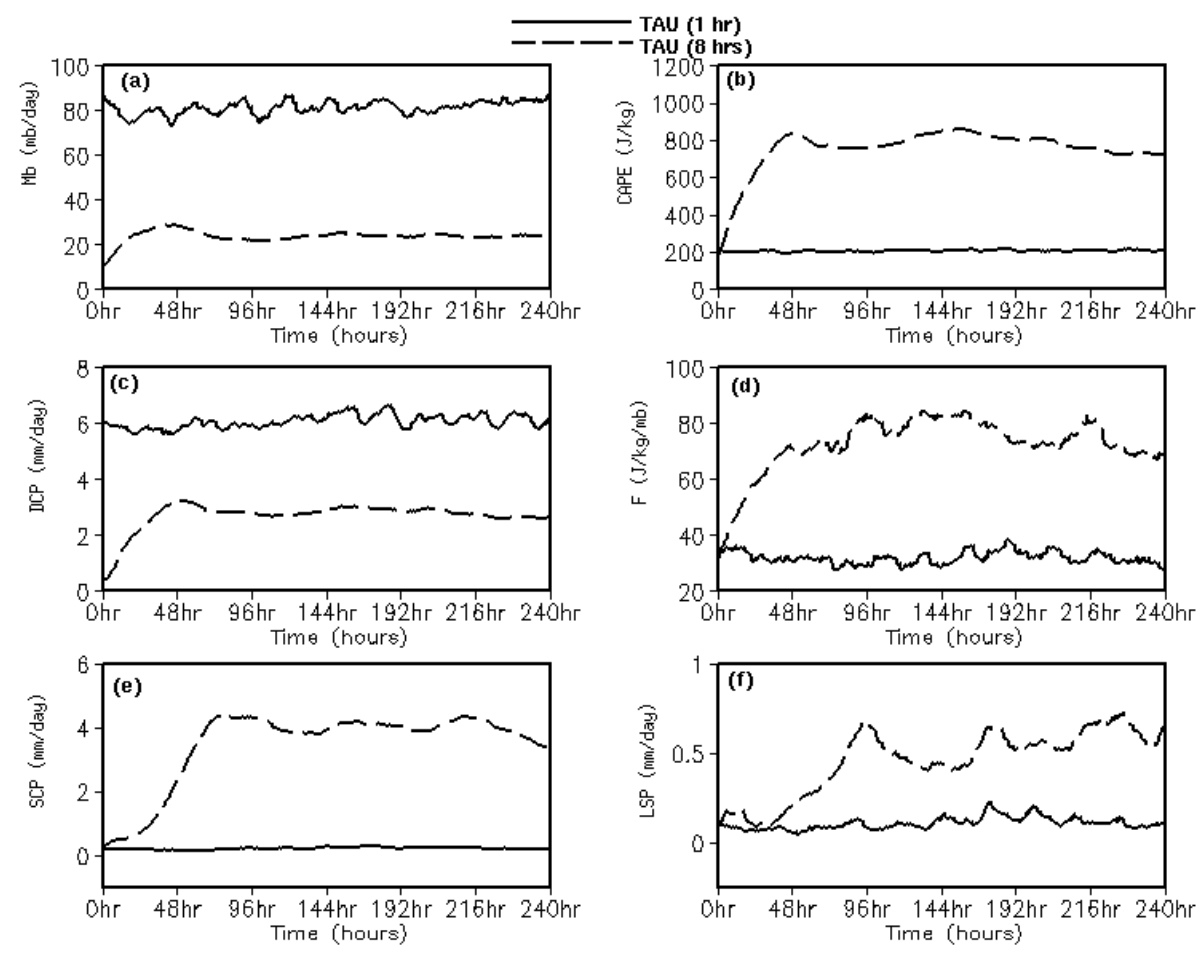

Fig. 15. Time evolution of area $\left(12^{\circ} \mathrm{S}\right.$ to $12^{\circ} \mathrm{N}$ and $0^{\circ} \mathrm{E}$ to $\left.360^{\circ} \mathrm{E}\right)$ averaged quantities for integration with TAU $(1 \mathrm{~h})$ and TAU $(8 \mathrm{~h})$. (a) Cloud base mass flux (mb/day), (b) CAPE (J/Kg), (c) DCP. (d) $F$, which is CAPE consumption rate per unit cloud base mass flux $(\mathrm{J} / \mathrm{Kg} / \mathrm{Mb})$, (e) SCP, and (f) LSP. 

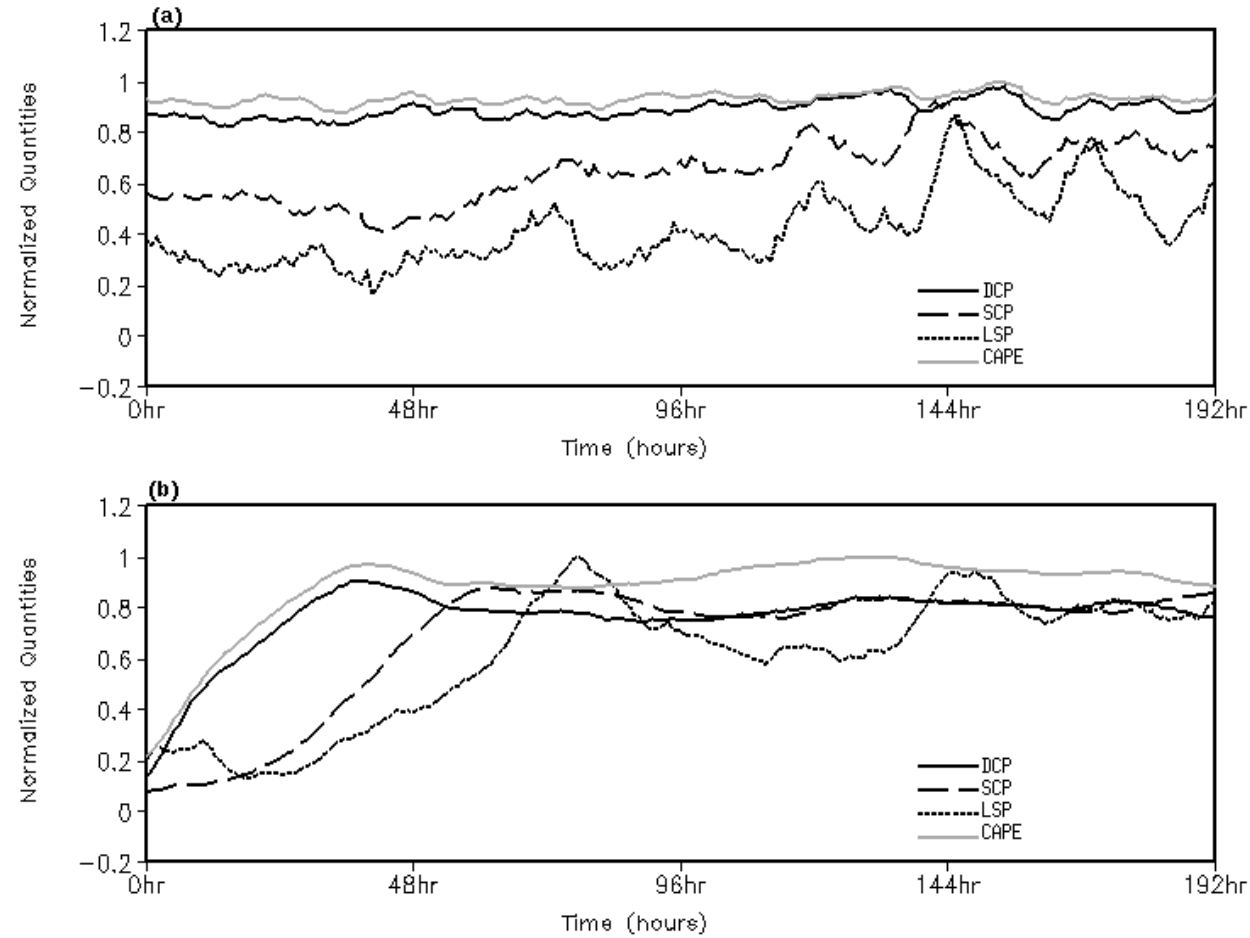

Fig. 16. Time evolution of area $\left(12^{\circ} \mathrm{S}\right.$ to $12^{\circ} \mathrm{N}$ and $0^{\circ} \mathrm{E}$ to $\left.360^{\circ} \mathrm{E}\right)$ averaged quantities. Shown quantities are normalized against their maximum values. (a) TAU (1 h), and (b) TAU ( $8 \mathrm{~h})$.
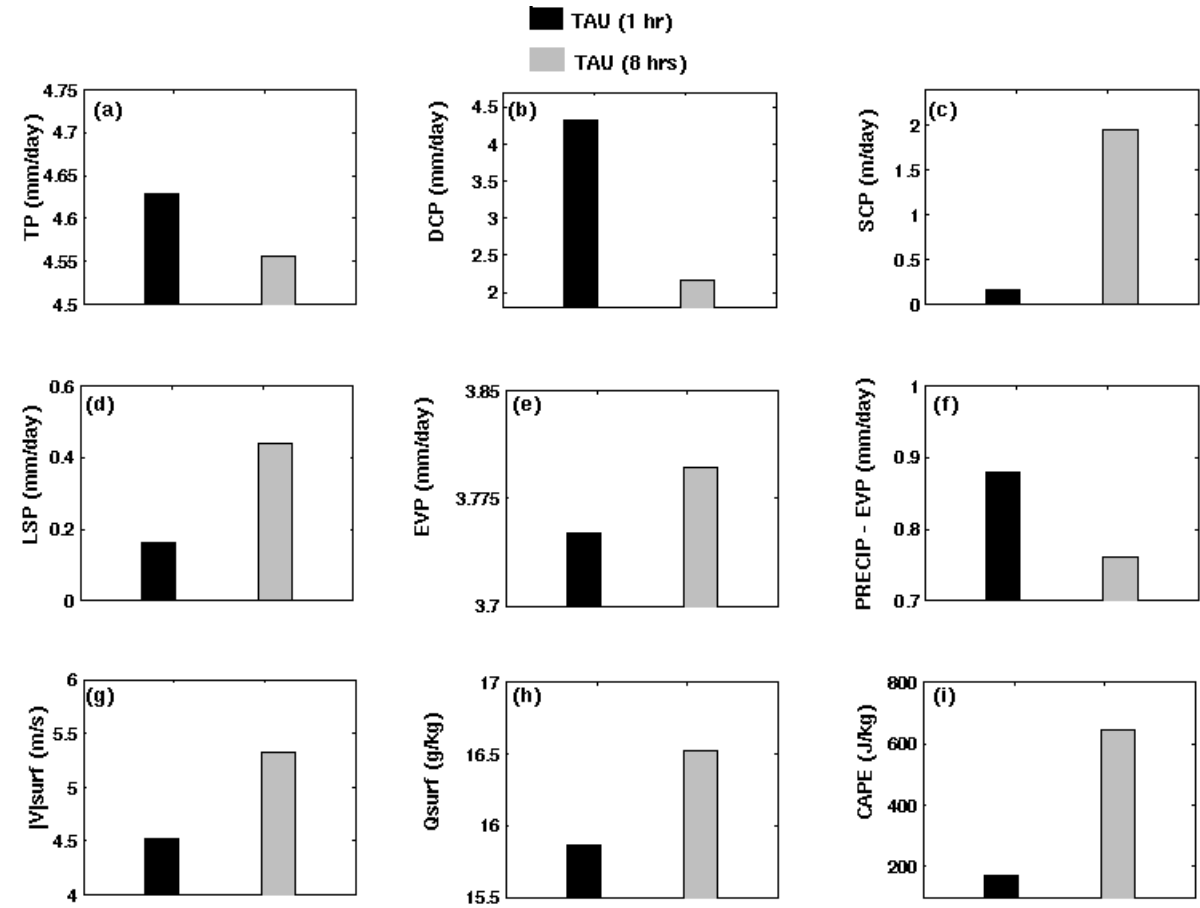

Fig. 17. Area averaged $\left(0^{\circ} \mathrm{E}\right.$ to $360^{\circ} \mathrm{E}$ and $12.5^{\circ} \mathrm{S}$ to $\left.12.5^{\circ} \mathrm{N}\right)$, time mean (all months of 10 years) quantities for TAU $(1 \mathrm{~h})$ and TAU $(8 \mathrm{~h})$. (a) TP, in this plot, (b) deep convective precipitation, (c) shallow convective precipitation, (d) large scale precipitation, (e) EVP, (f) PRECIP - EVP, (g) magnitude of wind at 1st model level, (h) specific humidity at the 1 st model level, and (i) CAPE. 

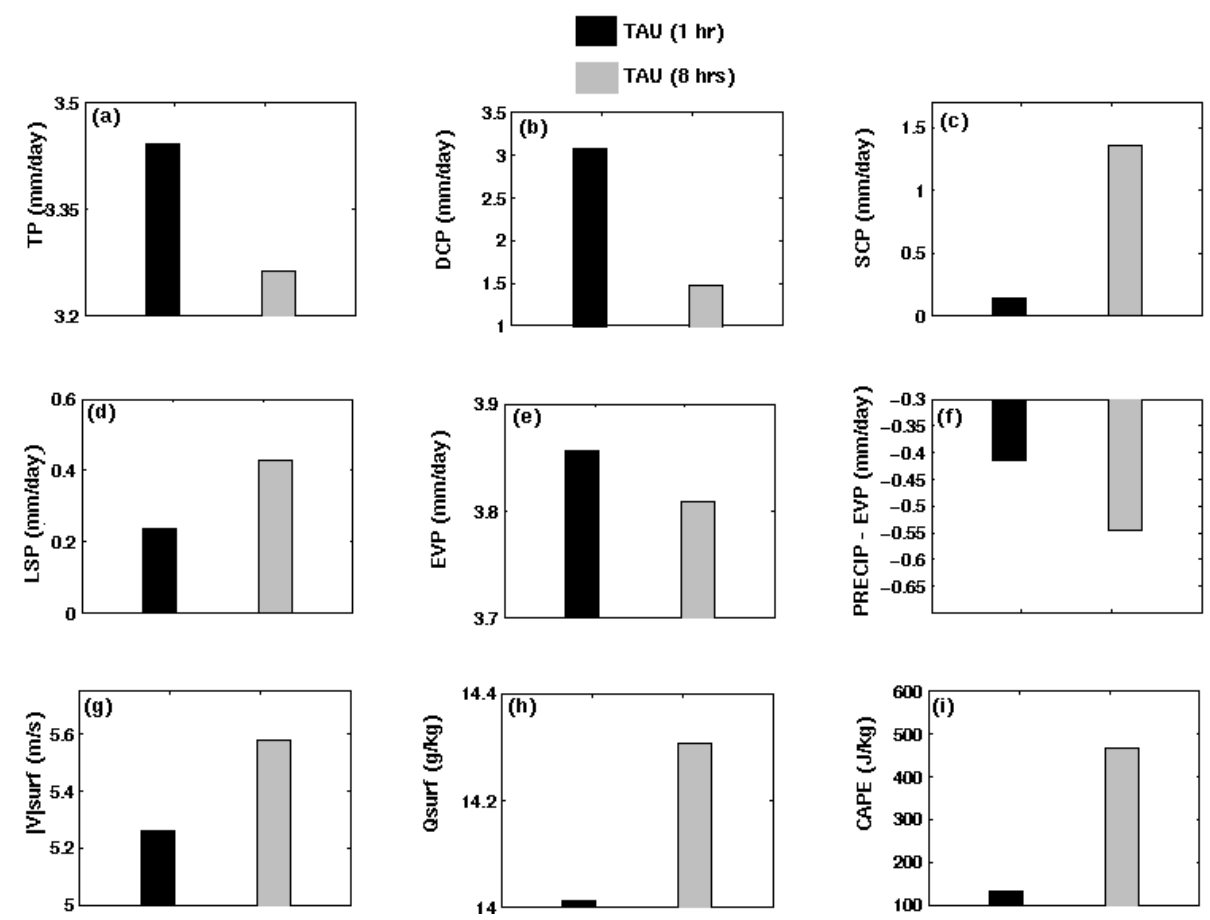

Fig. 18. Area averaged $\left(0^{\circ} \mathrm{E}\right.$ to $360^{\circ} \mathrm{E}$ and $30^{\circ} \mathrm{S}$ to $\left.30^{\circ} \mathrm{N}\right)$, time mean (all months of 10 years) quantities for TAU ( $\left.1 \mathrm{~h}\right)$ and TAU $(8 \mathrm{~h})$. (a) TP, in this plot, (b) deep convective precipitation, (c) shallow convective precipitation, (d) large scale precipitation, (e) EVP, (f) PRECIP - EVP, (g) magnitude of wind at 1st model level, (h) specific humidity at the 1st model level, and (i) CAPE.

the strength of maximum omega. The maximum omega in TAU $(1 \mathrm{~h})$ is -0.08 to $-0.09 \mathrm{~Pa} / \mathrm{s}$, whereas, in TAU $(8 \mathrm{~h})$, it is $-0.15 \mathrm{~Pa} / \mathrm{s}$ (see Figs. 4.16a1, and a2).

Figure $13 \mathrm{~b} 1$ and $\mathrm{b} 2$ shows the latitude-height section of the heating rate due to the moist processes, for both the cases. The background gray shading indicates the negative heating due to the evaporation of falling precipitation and melting of the precipitating ice. In TAU $(1 \mathrm{~h})$, the primary heating occurs in the upper troposphere, and the secondary in the lower troposphere, whereas, in TAU $(8 \mathrm{~h})$, the reverse is true.

Besides heating due to moist processes, there are some other heating terms in the model equations, e.g., solar radiation, long wave radiation, diffusion and KE dissipation, and temperature advection, which are not shown here. However, the moist heating is found to be the most important term and largely resembles the structure of omega. Hence, it can be inferred that the structure of omega is primarily governed by the distribution of moist heating.

\subsubsection{Vertical distribution of precipitation production}

Moist heating comprises of the heating due to DCP, SCP and LSP. Moreover, it also includes the negative heating due to re-evaporation and the $( \pm$ )ve heating associated with the freezing/melting of falling precipitation. In Fig. 14 the vertical distribution of the aforementioned precipitation components are shown individually. With increase of TAU, the fol- lowing can be noted from the figure: (1) DCP is decreasing largely throughout the troposphere, (2) SCP is increasing significantly in the lower- and mid-troposphere, and (3) LSP is increasing in the mid-troposphere. It is also noteworthy that, the magnitude of SCP is approximately one order higher than LSP.

In TAU (1 h), the evaporation of shallow and large scale precipitation (see Fig. 14b1 and c1, respectively) does occur in the lower mid-troposphere, which is the reason behind the occurrence of primary peak in heating in the upper troposphere, and the bi-modal heating structure. In TAU $(8 \mathrm{~h})$, most of the precipitation occurs in the lower to mid troposphere by shallow convection (see Fig. 14b2). A small amount of low-level evaporation of large-scale precipitation is noticed in TAU ( $8 \mathrm{~h}$ ), which is adjacent to the surface.

\subsection{Evolution during spin-up}

To understand the impact of change in TAU the evolution of various parameters during the spin-up period was examined. For this, the hourly model output of both the simulations i.e., TAU $(1 \mathrm{~h})$ and TAU $(8 \mathrm{~h})$, were analyzed. Both the simulations were started from the same initial conditions, which were prepared from a 5-year long integration in aqua-planet mode with the default parameter settings. Thus, TAU $(1 \mathrm{~h})$ simulation is basically the continuation of the previous run, whereas, TAU $(8 \mathrm{~h})$ simulation is a new run. In Fig. 15, the 
DIFFS $=$ TAU $(8 \mathrm{hrs})-$ TAU $(1 \mathrm{hr})$
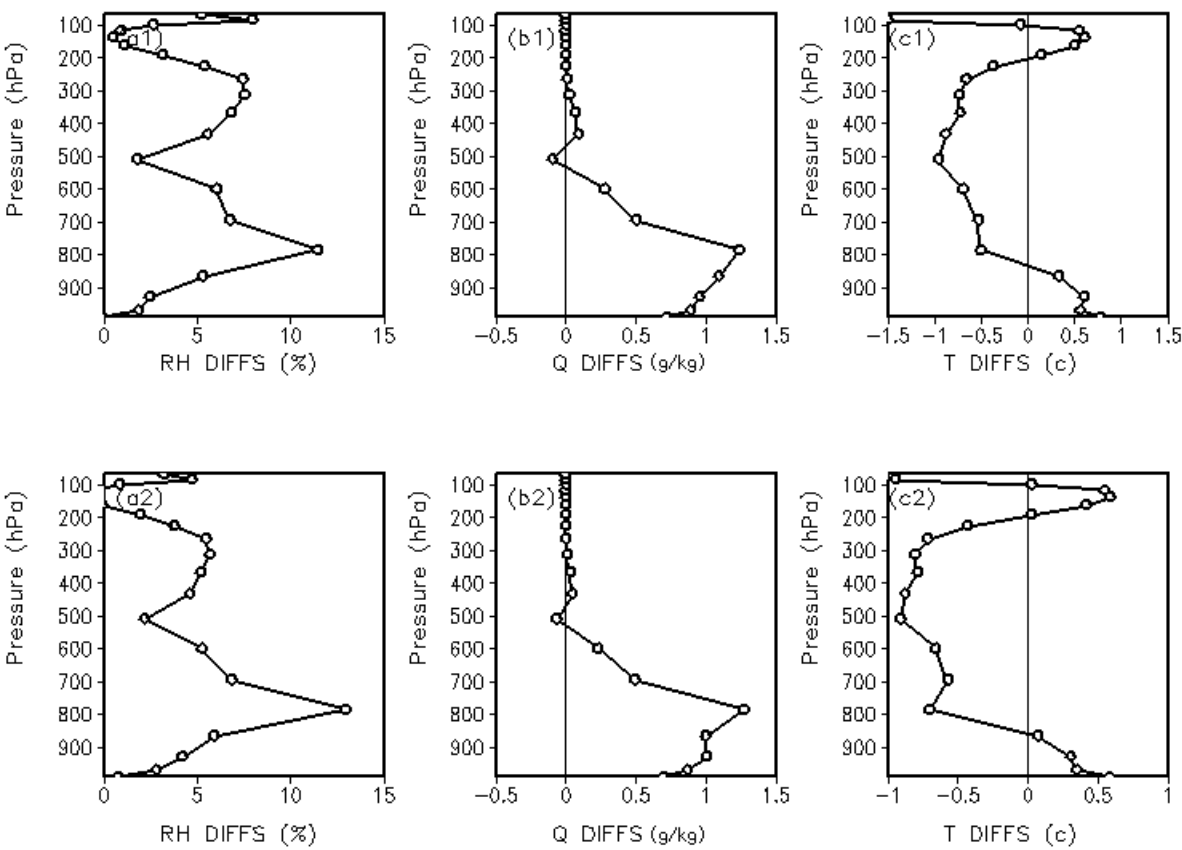

Fig. 19. Vertical profile of the difference of the area averaged, time mean, quantities between TAU $(8 \mathrm{~h})$ and TAU (1 h), at the raining points. grid points where the total precipitation is more than $1 \mathrm{~mm} /$ day are considered as the raining points. Top panel for the deep tropics $\left(0^{\circ} \mathrm{E}\right.$ to $360^{\circ} \mathrm{E}$ and $12.5^{\circ} \mathrm{S}$ to $\left.12.5^{\circ} \mathrm{N}\right)$ and bottom panel for the whole tropics $\left(0^{\circ} \mathrm{E}\right.$ to $360^{\circ} \mathrm{E}$ and $30^{\circ} \mathrm{S}$ to $\left.30^{\circ} \mathrm{N}\right)$. (a1) and (a2) $\mathrm{RH}$ difference $(\%)$, (b1) and (b2) specific humidity difference (gram/kg), (c1) and (c2) atmospheric temperature difference $\left({ }^{\circ} \mathrm{C}\right)$. Time mean is calculated by averaging over all the months of 10 years.

evolution of cloud base mass flux, DCP, SCP, CAPE, CAPE consumption rate per unit cloud base mass flux, and LSP, has been shown. Each of the variables shown is found to reach a quasi-steady state within the 96th hour of model integration.

From Fig. 15a and c, respectively, it can be seen that, at time $t=0 \mathrm{~h}$, there is a difference in cloud base mass flux and DCP, whereas all other variables shown in the figure are same in both the cases. Subsequently, difference in all other variables started showing up, which was seen to grow in time and arrive at their equilibrium level after a few hours of model integration. In Sect. 4.2, the computation of DCP has been illustrated, where Eq. (3) determines the cloud base mass flux. At time $t=0 \mathrm{~h}, \mathrm{CAPE}$ and CAPE consumption rate were same (see Fig. 15b and d), so higher TAU leads to lower cloud base mass flux. Equation (5) determines the DCP, which depends upon $\mathrm{C} 0$, updraft mass flux, and cloud liquid water. $C 0$ is a constant parameter and same for both the simulations, and cloud liquid water was also found to be same at time $t=0 \mathrm{~h}$ (not shown here). Updraft mass flux depends upon cloud base mass flux and lateral mixing due to entrainment and detrainment. We observed at time $t=0$ that, the lateral mixing is same for both the cases. However, cloud base mass flux is lower in TAU $(8 \mathrm{~h})$, which leads to a lower updraft mass flux. A lower value of updraft mass flux, in turn leads to lower DCP. Since convective precipitation consumes
CAPE, decrease in DCP results in increase of CAPE (see Fig. 15b), which in turn increases the DCP, and CAPE consumption rate (see Fig. $15 \mathrm{c}$ and d). This process continues till a quasi-steady state is reached, which happens at around the 96th hour (see Fig. 15f). During this time, SCP and LSP also increase, because of the increase in the instability of the atmosphere (measured in terms of CAPE).

Figure 16 shows the evolution of the normalized DCP, SCP, LSP, and CAPE to illustrate the lead-lag between them. Top panel (Fig. 16a) is for TAU $(1 \mathrm{~h})$, and the bottom panel (Fig. 16b) is for TAU ( $8 \mathrm{~h})$. As discussed above, TAU $(1 \mathrm{~h})$ does not show any major change, which is because of the fact that, it is the continuation of the previous run from where the initial conditions were extracted. However, the simulation with TAU ( $8 \mathrm{~h}$ ) shows an increase in CAPE followed by an increase in DCP, followed by an increase in SCP and then an increase in LSP.

\subsection{Actual-planet simulations}

To understand how the impact of TAU in aqua-planet translates to the real Earth, simulations were performed with actual land and sea-ice distribution, and fully interactive physics. Several numerical experiments were performed, with climatological and observed SSTs. The model was 


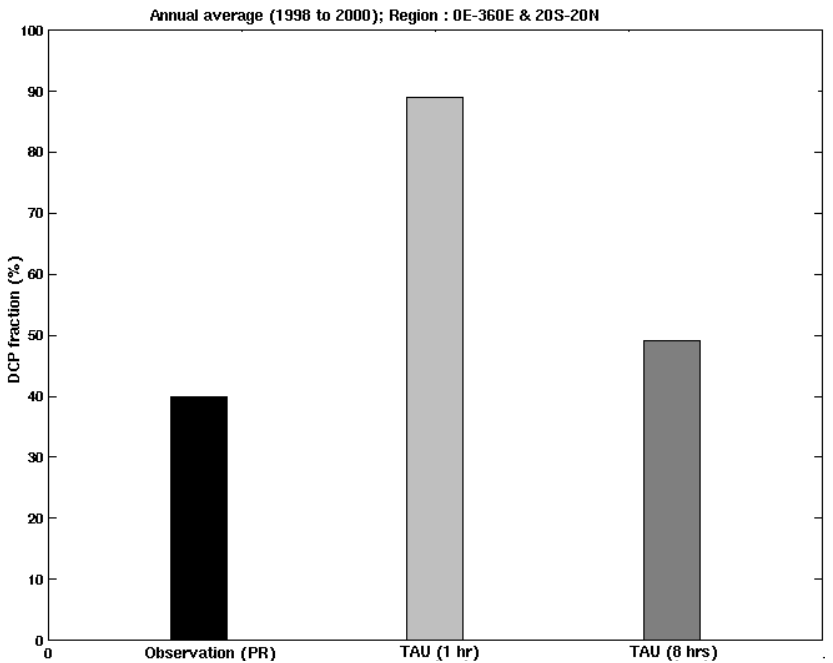

Fig. 20. Area averaged $\left(0^{\circ} \mathrm{E}\right.$ to $360^{\circ} \mathrm{E}$ and $20^{\circ} \mathrm{S}$ to $\left.20^{\circ} \mathrm{N}\right)$, time mean (all months) deep convective precipitation fraction from observation (PR), TAU (1 h) and TAU ( $8 \mathrm{~h})$.

integrated for 10 years with the climatological SST, and for 10 years with the observed SST, with TAU $(1 \mathrm{~h})$ and TAU (8h).

\subsubsection{Area integrated precipitation}

Monthly data of 10 years from the climatological SST simulations were analyzed to address the impact of TAU on the area-integrated precipitation. Figure 17 shows the impact on precipitation and its associated variables in the deep tropics $\left(12.5^{\circ} \mathrm{S}\right.$ to $\left.12.5^{\circ} \mathrm{N}\right)$. From this figure it is seen that TP is largely same, the change being less than $2 \%$ of the mean TP (see Fig. 17a). DCP is found to decrease (see Fig. 17b), and SCP and LSP are found to increase with increase in TAU (see Figs. $17 \mathrm{c}, \mathrm{d}$ ). So, it is inferred that TP is insensitive to TAU due to the compensation between the three components of precipitation. Figure 17e shows that, there is an increase in evaporation over the region. Hence large-scale convergence [PRECIP-EVP] is reduced (see Fig. 17f). The increase in evaporation is found to be due to the enhancement in wind strength at 1 st model level (see Fig. 17g). Surface evaporation is a function of wind strength and humidity. The specific humidity is higher at the 1st model level (see plot h), thus reducing the moisture deficit. Hence, it is inferred that the increase in evaporation is due to the increase in wind strength at the 1 st model level. Figure 17i shows that increase in TAU leads to increase in CAPE. This finding is similar to those found in aqua-planet simulations.

Figure 18 shows the response of the above-discussed variables in the whole tropics $\left(0^{\circ} \mathrm{E}\right.$ to $360^{\circ} \mathrm{E}$ and $30^{\circ} \mathrm{S}$ to $\left.30^{\circ} \mathrm{N}\right)$. It is noticed that, DCP is decreasing (see plot b), and SCP and LSP are increasing (see Fig. 18c and d), with increase in TAU. However, TP is found to decrease by $\sim 5 \%$ (see
Fig. 18a). Evaporation is found to decrease (see Fig. 18e), whereas, wind strength at the 1st model level is found to increase (see plot g). Figure $18 \mathrm{~h}$ shows that specific humidity in the 1st model level is increasing, which means reduction in the moisture deficit at the 1st model level. Hence, it is inferred that, the response of evaporation is due to the dominance of the response of specific humidity over the wind strength at the 1 st model level. Since, in the deep tropics there is an enhancement of evaporation, it could be because of the opposite response in the rest of the tropics (from $12.5^{\circ} \mathrm{N} / \mathrm{S}$ to $30^{\circ} \mathrm{N} / \mathrm{S}$ ). Figure $18 \mathrm{f}$ shows the enhancement in the large-scale moisture divergence. The increase in CAPE with increase of TAU can be seen from Fig. 18i.

Figure 19 shows the vertical profile of the difference in $\mathrm{RH}, Q$, and $T$, for deep tropics (in top panel), and for the whole tropics (bottom panel). Increase of TAU leads to increase in RH throughout the atmosphere (see Fig. 19a1 and 19a2). Specific humidity $(Q)$, is found to increase below $500 \mathrm{hPa}$, (see plot b1 and b2). Temperature $(T)$ is noticed to have increased in the lower (below $850 \mathrm{hPa}$ ), and upper $(200-100 \mathrm{hPa})$ troposphere, whereas, in between it gets reduced with increase in TAU. So, the increase in RH in the lower troposphere is attributable to the increase in $Q$, but in the middle troposphere, it is primarily attributable to the decrease in $T$. In the upper troposphere, the increase in $\mathrm{RH}$ is due to the increase in $Q$, (not shown here). However, an exception is plot (a2), which shows a slight decrease of $\mathrm{RH}$ between 100 to $200 \mathrm{hPa}$, which is because of the dominant effect of increase in temperature (see Fig. 19c2) over the small increase in $Q$ (see Fig. 19b2) at those levels.

Rasch et al. (2006) showed that the proportion of precipitation components in CAM3 is not satisfactorily simulated, though the simulated total precipitation is in close agreement with the observation. We noticed that TAU affects the proportion of the precipitation components, by keeping the TP by and large the same. In Fig. 20, the fraction of deep convective precipitation is shown from observation (TRMM Precipitation Radar), TAU ( $1 \mathrm{~h})$ and TAU $(8 \mathrm{~h})$. TRMM product 2A23 places the majority of the shallow convective clouds in the stratiform subcategory (Schumacher and Houze, 2003). So, to compare with the TRMM data, we use similar classification of the TP i.e. deep convective and remaining as stratiform. Figure 20 shows that, in observation the DCP is around $40 \%$ whereas in TAU $(1 \mathrm{~h})$ it is around $90 \%$. This is in agreement with the results shown by Rasch et al. (2006). However, in TAU ( $8 \mathrm{~h}$ ), proportion of DCP is seen to be around $50 \%$, which is very close to the observation.

\subsubsection{Seasonal mean simulation}

To see the response of the seasonal mean precipitation distribution, we analyzed 10-years (1979 to 1988), data from the observed SST simulations, with TAU $(1 \mathrm{~h})$ and TAU $(8 \mathrm{~h})$. The comparisons with CMAP estimates are shown. 

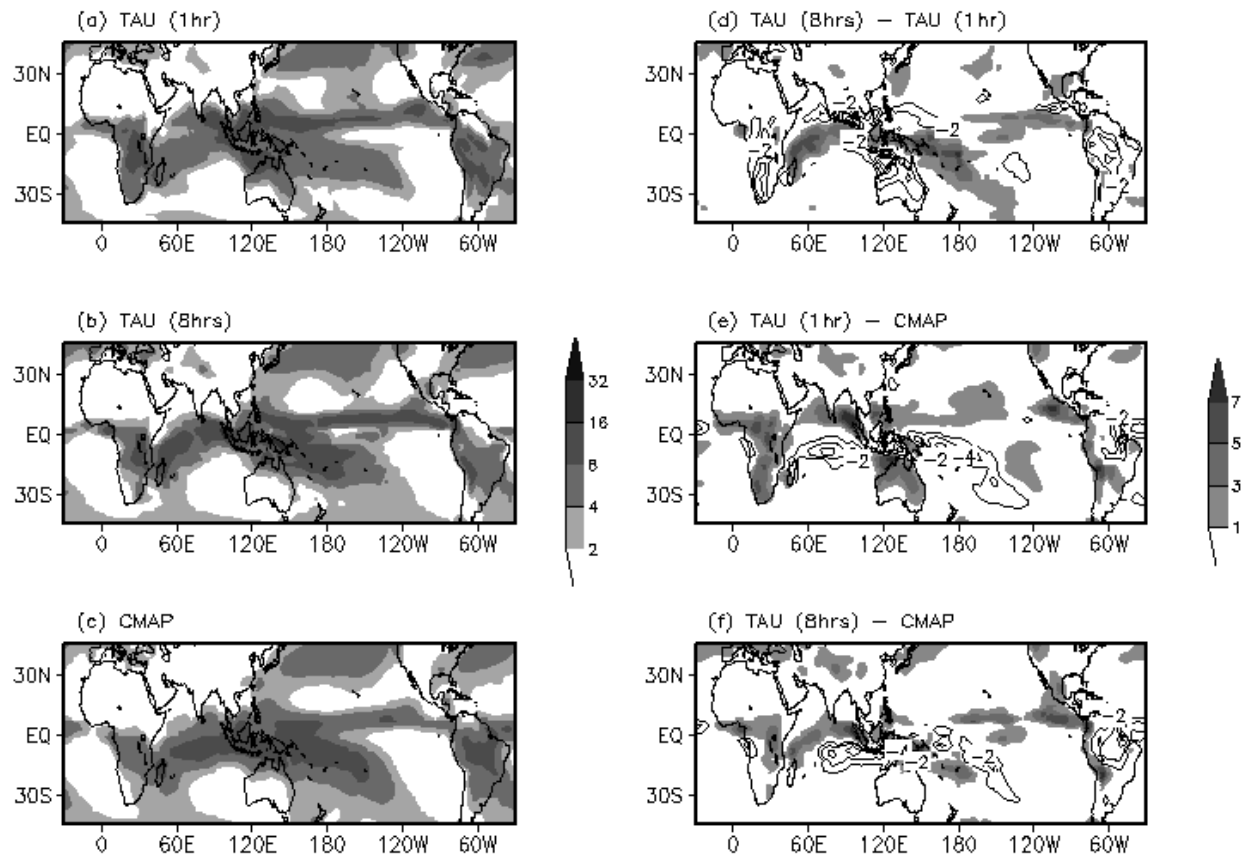

Pattern correlation between CMAP \& TAU (1hr) $=0.79$

Pattern correlation between CMAP \& TAU ( $8 \mathrm{hrs})=0.83$

Fig. 21. Climatological mean DJF precipitation (mm/day) for (a) TAU (1 h), (b) TAU ( 8 h), (c) CMAP, (d) [TAU (8 h) - TAU (1 h)], (e) [TAU (1 h) - CMAP], and (f) [TAU ( $8 \mathrm{~h})$ - CMAP]. The climatological mean is derived from 10 years (1979 to 1988).
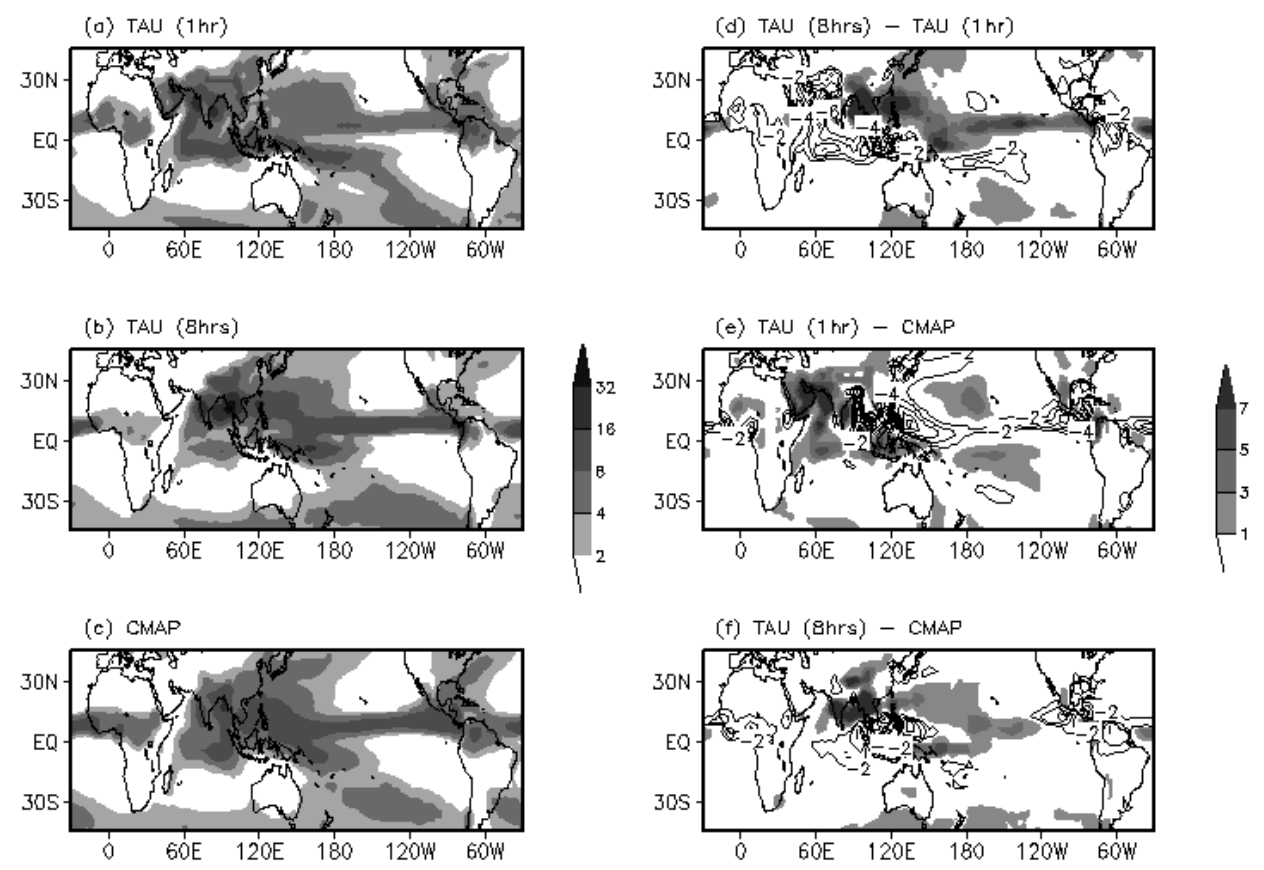

Pattern correlation between CMAP \& TAU(1hr) $=0.67$

Fig. 22. Climatological mean JJA precipitation (mm/day) for (a) TAU (1 h), (b) TAU ( 8 h), (c) CMAP, (d) [TAU (8 h) - TAU (1 h)], (e) [TAU (1 h) - CMAP], and (f) [TAU $(8 \mathrm{~h})$ - CMAP]. The climatological mean is derived from 10 years (1979 to 1988). 

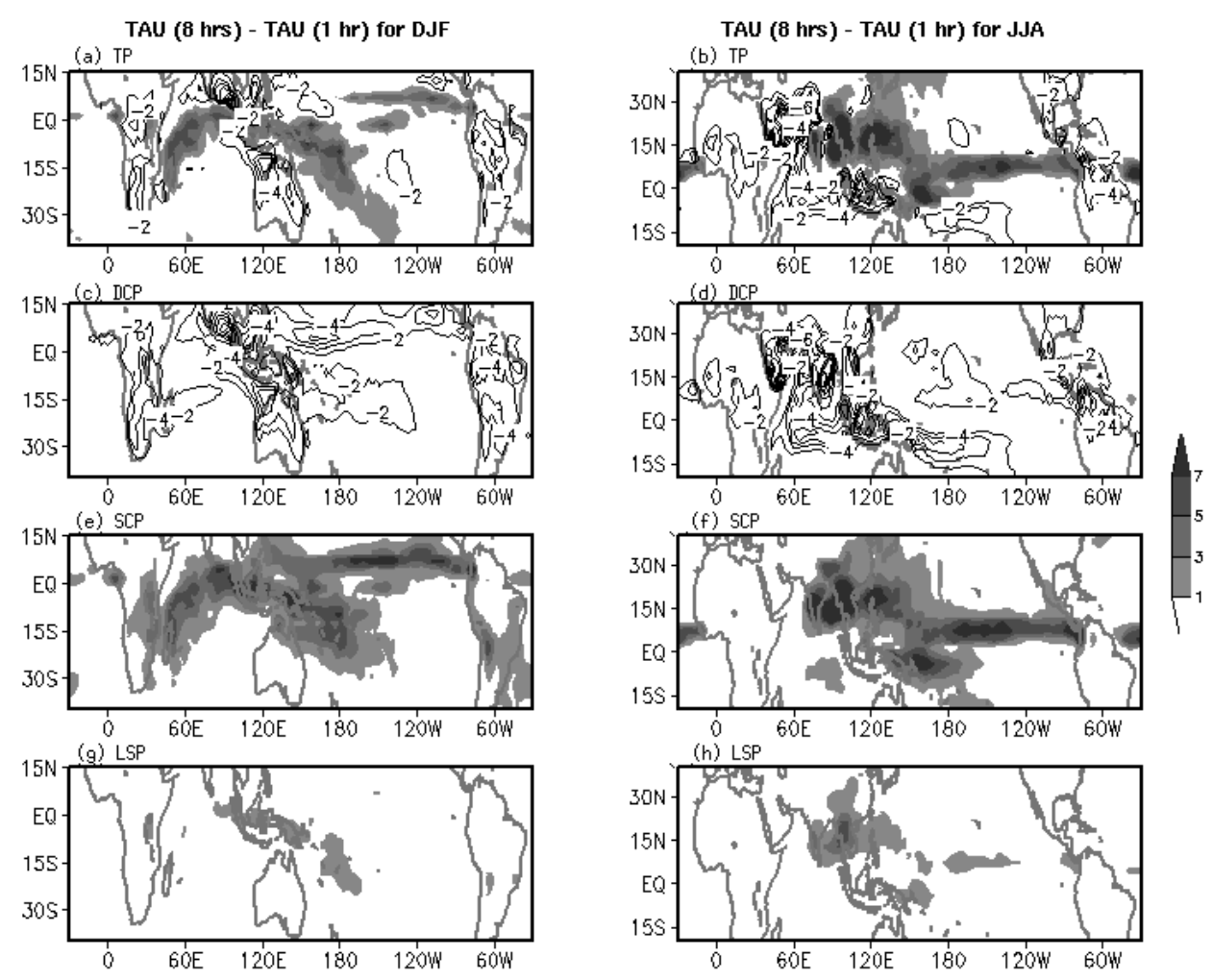

Fig. 23. Difference in the Climatologically mean precipitation ( $\mathrm{mm} /$ day) between TAU $(8 \mathrm{~h})$ and TAU (1 h). The left panel is for DJF and the right panel for JJA. (a) and (b) Total precipitation, (c) and (d) Convective precipitation, and (e) and (f) Large-scale precipitation. The climatological mean is derived from 10 years (1979 to 1988).

From Fig. 21a, it is noticed that, the control simulation successfully captures many of the observed features during Northern Hemisphere winter, e.g., south Pacific and south Atlantic convergence zones, precipitation minima over the sub-tropics of the eastern parts of the oceans of both the hemispheres. Similarly Fig. 22a shows that, the control simulation captures the broad features of Northern Hemisphere summer e.g., precipitation maxima along $10^{\circ} \mathrm{N}$, strong precipitation over western Pacific, precipitation over eastern Pacific, and precipitation minima over the sub-tropical eastern parts of the oceans in both the hemispheres. These are found to be consistent with the previous studies e.g., Hurrell et al. (2006), Rasch et al. (2006), Hack et al. (2006), Collins et al. (2006), and Meehl et al. (2006).

However, there do exist many biases (Hurrell et al., 2006). During northern winter, the precipitation over the south of the equator between $60^{\circ} \mathrm{E}$ to $120^{\circ} \mathrm{W}$ is underestimated, and over tropical Africa, northern Australia, and north of the equator over the western Pacific, it is overestimated. Similarly, during northern summer, over the equatorial zone of western, eastern, and central Pacific, and eastern and head of the Bay of Bengal, the model underestimates the precipitation. Over Saudi Arabia, western Indian Ocean, western Arabian sea, and western part of south Pacific, the precipitation is overestimated.
From Fig. 21, it was noticed that, increase of TAU leads to increase in precipitation south of the equator between $60^{\circ} \mathrm{E}$ to $120^{\circ} \mathrm{W}$, and south Pacific convergence zone. On the other hand, there is a decrease in precipitation over tropical Africa, northern Australia, and north of the equator over the western Pacific. These changes seem to rectify some of the existing biases of the model. However, along with this, there is also an increase in precipitation over the eastern Pacific, resulting in a positive bias. Since some of the existing biases have been rectified, the pattern correlation is found to be better with TAU ( 8 h) i.e., from 0.79 it has increased to 0.83 (see bottom of the Fig. 21).

It is noticed from Fig. 22 that increase of TAU increases the precipitation over the equatorial belts of western, eastern, and central Pacific. It also increases the precipitation over the eastern coast and north Bay of Bengal, and over the Indian subcontinent. Over tropical Africa, Saudi Arabia, equatorial Indian ocean, western parts of the south Pacific, the precipitation decreases with increase of TAU. These changes, rectifies some of the aforementioned model biases and improve the pattern correlation coefficient from 0.67 to 0.79 .

Figure 23 shows the contribution of each of the precipitation components to the above effects. It is notable that, over the whole domain, and in both the seasons, DCP gets reduced and SCP and LSP get enhanced with increase in TAU. The 
positive biases are rectified by the reduction of the DCP and the negative biases are rectified by the enhancement of SCP and LSP. However, comparatively the contribution of SCP is much higher than that of LSP.

\section{Conclusions}

The sensitivity of the simulated precipitation to changes in convective relaxation time scale (TAU) of Zhang and McFarlane (ZM) cumulus scheme in NCAR-Community Atmosphere Model version 3 (CAM3) was examined. The investigation was carried out in two modeling frameworks i.e., aqua-planet and actual-planet. A series of numerical experiments were conducted in the aqua-planet mode by increasing TAU from $1 \mathrm{~h}$ (default value) up to infinity, and its impact on simulated precipitation was examined. The deep convective precipitation (DCP) was found to decrease with an increase in TAU. This leads to an accumulation of convective instability and moisture content in the atmosphere. Consequently, the shallow convective precipitation (SCP) and large-scale precipitation (LSP) intensify and cap the accumulation of convective instability. The decrease in DCP and increase in SCP and LSP, have a compensating effect, and thus the net surface reaching total precipitation (TP) is insensitive to TAU. Comparatively the magnitude of the increase in SCP is one order higher than that of LSP. Thus, it is the enhancement of SCP that primarily compensates the decrease of DCP. The DCP occurs throughout the troposphere, with peak in the upper levels, whereas SCP mainly occurs in the lower- and midtroposphere. So, when TAU was increased, DCP decreased throughout the troposphere but SCP increased in the lower and mid-troposphere. Hence, even though the surface reaching TP remains same, there is a change in the vertical distribution of the total precipitation. As a result, the moist heating increases in the lower and mid troposphere and decreases in the upper troposphere. The vertical velocity intensifies in the lower troposphere and the meridional circulation becomes stronger.

In order to verify if the effects of TAU on simulated precipitation in an aqua-planet framework translate to a real-planet, numerical integrations were carried out with actual landocean distribution, observed sea surface temperatures containing the annually varying seasonal cycle, and fully interactive physics. The model was integrated for 10 years (January 1979 to December 1988), with TAU $=1 \mathrm{~h}$ in one experiment, and with TAU $=8 \mathrm{~h}$ in the other. The seasonal mean precipitation was analyzed and compared with observed values (CMAP). The seasonal mean precipitation with TAU $=8 \mathrm{~h}$ was found to be more realistic. In a previous study, we have shown that some of the variability aspects (convectively coupled equatorial waves) of simulated climate become more reasonable with TAU $=8 \mathrm{~h}$ (Mishra, 2007). However, for values of TAU greater than $8 \mathrm{~h}$, the quality of model simulations was found to deteriorate. Since the current work was car- ried out with a model spectral resolution of T63 (equivalent grid spacing of $\sim 280 \mathrm{~km}$ ), it seems that $8 \mathrm{~h}$ is the optimum value for $280 \mathrm{~km}$ horizontal grid spacing. Future work will focus on determining the optimum value of TAU and its dependence on model resolution.

Acknowledgements. The first author (SKM) thanks Sandeep Sahany (of UCLA), Brian Mapes (of Univ. of Miami), and Joe Tribbia (of NCAR) for helpful discussions on the related topics. The encouragement and support of Henry Tufo (of NCAR) and Ram Nair (of NCAR) is sincerely appreciated. The authors gratefully acknowledge the helpful comments and suggestions of the two anonymous referees and Paolo Michele Ruti (topical editor).

Topical Editor P. M. Ruti thanks two anonymous referees for their help in evaluating this paper.

\section{References}

Arakawa, A.: The cumulus parameterization past present, and future, J. Climate, 17, 2493-2525, 2004.

Betts, A. K.: A new convective adjustment scheme. Part I: Observational and theoretical basis, Q. J. Roy. Meteorol. Soc., 112, 677-692, 1986.

Betts, A. K. and Miller, M. J.: A new convective adjustment scheme. Part II: Single column tests using GATE-wave, BOMEX, ATEX, and Arctic Airmass data sets, Q. J. Roy. Meteorol. Soc., 112, 693-710, 1986.

Boville, B. A. and Bretherton, C. S.: Heating and dissipation in the NCAR community atmosphere model, J. Climate, 16, 38773887, 2003.

Bretherton, C. S., Peters, M. E., and Back, L. E.: Relationships between water vapor path and precipitation over the tropical oceans, J. Climate, 17, 1517-1528, 2004.

Brown, R. G. and Bretherton, C. S.: A test of the strict quasiequilibrium theory on long time and space scales, J. Atmos. Sci., 54, 624-638, 1997.

Collins, W. D., Rasch, P. J., Eaton, B. E., et al.: Simulation of aerosol distributions and radiative forcing for INDOEX: Regional climate impacts, J. Geophys. Res., 107, 8028, doi:10.1029/2000JD000032, 2002.

Collins, W. D., Rasch, P. J., Boville, B. A., et al.: Description of the NCAR Community Atmosphere Model (CAM 3.0), NCAR Technical Note, NCAR/TN-464+STR, 226 pp., 2004.

Collins, W. D., Rasch, P. J., Boville, B. A., et al.: The formulation and atmospheric simulation of the Community Atmosphere Model: CAM3, J. Climate, 19, 2144-2161, 2006.

Frierson, D. M. W.: The Dynamics of Idealized convection scheme on the zonally averaged tropical circulation, J. Atmos. Sci., 64, 1959-1976, 2007.

Gates, W. L.: AMIP: the atmospheric model intercomparsion project, B. Am. Meteorol. Soc., 73, 1962-1970, 1992.

Hack, J. J.: Parameterization of moist convection in the National Center for Atmospheric Research Community Climate Model (CCM2), J. Geophys. Res., 99, 5551-5568, 1994.

Hack, J. J., Caron, J. M., Yeager, S. G., et al.: Simulation of the global hydrological cycle in the CCSM Community Atmosphere Model Version 3 (CAM3): Mean Features, J. Climate, 19, 2199_ 2221, 2006. 
Houze Jr., R. A.: Stratiform precipitation in regions of convection: A meteorological paradox?, B. Am. Meteorol. Soc., 78, 21792196, 1997.

Hurrell, J. W., Hack, J. J., Phillips, A. S., Caron, J., and Yin, J.: The Dynamical Simulation of the Community Atmosphere Model Version 3 (CAM3), J. Climate, 19, 2162-2183, 2006.

Johnson, R. H.: Partitioning tropical heat and moisture budgets into cumulus and mesoscale components: Implication for cumulus parameterization, Mon. Weather Rev., 112, 1590-1601, 1984.

Lee, J.-E., Pierrehumbert, R., Swann, A., and Lintner, B. R.: Sensitivity of stable water isotopic values to convective parameterization schemes, Geophys. Res. Lett., 36, L23801, doi:10.1029/2009GL040880, 2009.

Lin, J. L., Mapes, B. E., Zhang, M., and Newman, M.: Stratiform precipitation, vertical heating profiles, and the Madden-Julian Oscillation, J. Atmos. Sci., 61, 296-309, 2004.

Locatelli, J. D. and Hobbs, P. V.: Fall Speeds and Masses of Solid Precipitation Particles, J. Geophys. Res., 79, 2185-2197, 1974.

Lorant, V., McFarlane, N. A., and Scinocca, J. F.: Variability of precipitation intensity: sensitivity to treatment of moist convection in an RCM and a GCM, Clim. Dynam., 26, 183-200, 2006.

Mapes, B. E. and Houze Jr., R. A.: Cloud clusters and superclusters over the oceanic warm pool, Mon. Weather Rev., 121, 13981415, 1993.

Mapes, B. E. and Houze Jr., R. A.: Diabatic divergence profiles in western Pacific mesoscale convective systems, J. Atmos. Sci., 52, 1807-1828, 1995.

Mapes, B. E.: Empirical studies of unobservable parameters, 2001 ECMWF annual seminar course on physical parameterization, 2001.

McFarlane, N. A.: The effect of orographically excited gravity wave drag on the general circulation of the lower stratosphere and troposphere, J. Atmos. Sci., 44, 1775-1800, 1987.

Meehl, G. A., Arblaster, J. M., Lawrence, D. M., et al.: Monsoon regimes in the CCSM3, J. Climate, 19, 2482-2495, 2006.

Mishra, S. K.: The impact of convective relaxation time on the simulation of seasonal migration of ITCZ, MJO, and Kelvin waves in CAM3.0 An International Conference: Celebrating the Monsoon, IISc, Bangalore, http://www.image.ucar.edu/ $\sim$ saroj/ presentations.html, July 2007.

Mishra. S. K., Srinivasan, J., and Nanjundiah, R. S.: The impact of time step on the intensity of ITCZ in aqua-planet GCM, Mon. Weather Rev., 136, 4077-4091, 2008.
Neale, R. B.: A study of the tropical response in an idealized global circulation, PhD thesis, Department of Meteorology, University of Reading, UK, 1999.

Neale, R. B. and Hoskins, B. J.: A standard test for AGCMs including their physical parameterizations. I: The proposal, Atmos. Sci. Lett., 1, 101-107, 2000.

Rasch, P. J. and Kristjansson, J. E.: A comparison of the CCM3 model climate using diagnosed and predicted condensate parameterizations, J. Climate, 11, 1587-1613, 1998.

Rasch, P. J., Stevens, M. J., Ricciardulli, L., et al.: A Characterization of tropical transient activity in the CAM3 Atmospheric hydrologic cycle, J. Climate, 19, 2222-2242, 2006.

Rayner, N. A., Parker, D. E., Horton, E. B., et al.: Global analyses of sea surface temperature, sea ice, and night marine air temperature since the late nineteenth century, J. Geophys. Res., 108, 4407, doi:10.1029/2002JD002670, 2003.

Reynolds, R. W., Rayner, N. A., Smith, T. M., Stokes, D. C., and Wang, W.: An improved in situ and satellite SST analysis for climate, J. Climate, 15, 1609-1625, 2002.

Ricciardulli, L. and Garcia, R. R.: The excitation of equatorial waves by deep convection in the NCAR community climate model (CCM3), J. Atmos. Sci., 57, 3461-3487, 2000

Sahany, S. and Nanjundiah, R. S.: Impact of convective downdrafts on model simulations: results from aqua-planet integrations, Ann. Geophys., 26, 1877-1887, doi:10.5194/angeo-261877-2008, 2008.

Sundqvist, H.: Parameterization of condensation and associated clouds in models for weather prediction and general circulation simulation, in Physically-based Modeling and Simulation of Climate and Climate Change, vol.1, edited by: Schlesinger, M. E., 433-461, Kluwer Academic, 1998.

Williamson, D. L.: Time-split versus process-split coupling of parameterizations and dynamical core, Mon. Weather Rev., 130, 2024-2041, 2002.

Xie, P. and Arkin, P. A.: Global precipitation: a 17-year monthly analysis based on gauge observations, satellite estimates, and numerical model outputs, B. Am. Meteorol. Soc., 78, 2539-2558, 1996.

Zhang, G. J. and McFarlane, N. A.: Sensitivity of climate simulations to the parameterization of cumulus convection in the CCGCM, Atmos.-Ocean, 33, 407-446, 1995.

Zhang, M., Lin, W., Bretherton, C. S., Hack, J. J., and Rasch, P. J.: A modified formulation of fractional stratiform condensation rate in the NCAR Community Atmosphere Model CAM2, J. Geophys. Res., 108(D1), 4035, doi:10.1029/2002JD002523, 2003. 